\title{
Control of extracellular microenvironments using polymer/protein nanofilms for the development of three-dimensional human tissue chips
}

\author{
Michiya Matsusaki and Mitsuru Akashi \\ Cell functions, such as adhesion, migration, proliferation, differentiation, organization, protein expression and death, are \\ dynamically regulated at the surface of cell membranes by the interaction between a ligand molecule of the cellular \\ microenvironments and the membrane protein receptors. Furthermore, physical signals of cellular microenvironments, stiffness, \\ elasticity and hydration, are also important factors for the modulation of cellular functions. In the body, natural extracellular \\ matrices (ECMs) and ECM-bound growth factors regulate cell functions. The universal control of cell functions at the single-cell \\ level through the artificial modulation of extracellular microenvironments by mimicking the natural ECMs would be a key \\ technique for biomedical fields. In the present review, the fabrication of nanometer-sized artificial ECM films using various \\ polymers and proteins on single-cell surfaces to control cell functions is described. The thickness, charge and component of the \\ ECM films were observed to significantly affect the cell functions. Moreover, the optimized ECM films induced cell-cell \\ organization to construct three-dimensional human tissue chips. Control of extracellular microenvironments using a nanometer- \\ sized polymer/protein film as an artificial ECM would be useful as a novel technique to regulate cell functions as desired. \\ Polymer Journal (2014) 46, 524-536; doi:10.1038/pj.2014.20; published online 23 April 2014
}

Keywords: cell; layer-by-layer; nanofilms; tissue engineering

\section{INTRODUCTION}

Tissue cells in the body reside in the micrometer-sized fibrous meshwork of the extracellular matrix (ECM). Tissue dynamics, such as formation, function and regeneration after damage, are the result of an intricate temporal and spatial coordination of numerous individual cell fate processes, each of which is induced by a myriad of signals originating from the extracellular microenvironment (Scheme 1). ${ }^{1}$ The extracellular microenvironment is a hydrated protein and proteoglycan-based ECM gel network comprising soluble and physically bound signals as well as signals arising from cell-cell interactions. ${ }^{2}$ The ECM is typically composed of fibronectin (FN), collagen and laminin and provides complex biochemical and physical signals. ${ }^{3,4}$ The ECM not only stores growth factors and cytokines but also induces cell-cell contacts and cell-matrix interactions. $^{2}$ Accordingly, control of the cellular microenvironment using artificial ECM and growth factors will be an important in vitro technique to control cell growth, cytokine expression, stem cell differentiation and extracellular assembly. To control the cellular microenvironment, the patterning of substrate surfaces ${ }^{5}$ and the chemical modifications of cell surfaces ${ }^{6-8}$ have been generally used. However, substrate modification cannot modify the important cell apical membrane, and chemical modifications have limitations because of cytotoxicity, complicated methodology or less application.
We focused on the layer-by-layer (LbL) assembly technique of polymer or protein films to modify cell membranes. Decher et al. ${ }^{9-11}$ reported in 1991 that the stepwise immersion of substrates such as mica and glass into aqueous solutions of positively and negatively charged polymers produced multilayered ultrathin polymer films with a controllable nanometer thickness. This method is called LbL assembly, and both the basic research and applications have been widely developed in polymer science (Figure 1a). As this technique involves the simple immersion of a substrate into an oppositely charged polymer solution, researchers have extended LbL assembly to include the deposition of not only water-soluble linear charged polymers (polyelectrolyte, PE) but also viruses, ${ }^{12}$ proteins ${ }^{13,14}$ and nanoparticles. ${ }^{15,16}$ Initially, only electrostatic interactions were utilized for LbL assembly. Subsequently, other interactions such as hydrogen bonding, ${ }^{17,18}$ charge transfer, ${ }^{19,20}$ covalent bonding ${ }^{21,22}$ and Van der Waals interactions ${ }^{23-26}$ have been investigated to facilitate polymer association for ultrathin film deposition. The PE-LbL assemblies were applied for the surface modification of cells in 2001 for the first time, and red blood cells and bacteria were used for the fabrication of hollow microcapsules using this technique. ${ }^{27}$ The LbL assemblies have generally been used for the surface modification of microorganisms and yeasts ${ }^{28,29}$ due to the toxicity for fragile mammalian cells $^{30}$ because these cells do not have a strong cell wall structure. 
Thus, there have been few reports on the surface modification of mammalian cells with LbL films and further application for the biomedical field.

We fabricated LbL nanofilms on the surface of various mammalian cells by using a different driving force, biological recognition. The specific recognition of biological macromolecules such as proteinligand, antibody-antigen and protein-polysaccharide interactions are composed of multiple weak interactions such as electrostatic, hydrogen bonding and hydrophobic interactions and provide high specificity to the target macromolecules. These interactions would extend the scope of the LbL technique in constructing functional thin-film assemblies because non-ionic polymers and even polymers with the same polarity can be built into the same assemblies simultaneously via the biological interactions. A few reports have appeared on LbL assemblies based on such biological interactions, avidin-biotin, ${ }^{31-34}$ antibody-antigen, ${ }^{35,36}$ lectin-polysacccharides ${ }^{37,38}$ and ECM macromolecules. ${ }^{39}$

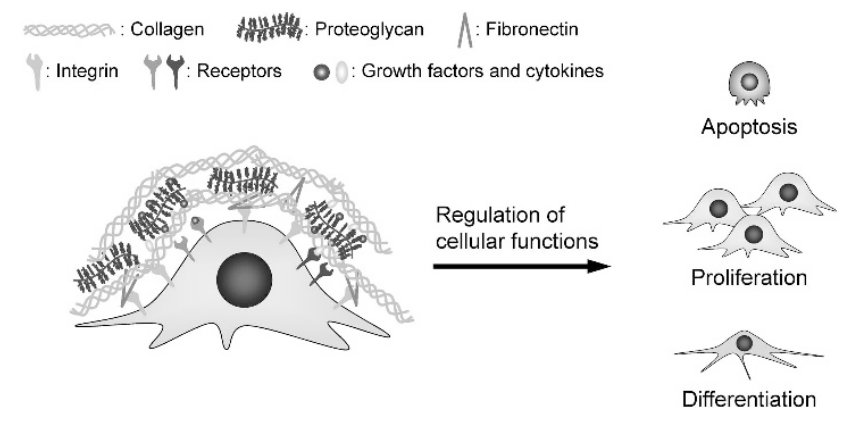

Scheme 1 Schematic illustration of extracellular microenvironments. A full color version of this figure is available at Polymer Journal online.
In this review, we describe LbL assemblies on cell surfaces using biological interaction, especially focusing on FN to control cellular functions. Moreover, the fabrication of three-dimensional (3D) tissue constructs was succeeded by controlling the cell-cell interaction through the FN-based LbL nanofilms.

\section{BIOLOGICAL RECOGNITION VS ELECTROSTATIC INTERACTION}

FN is a highly flexible multifunctional glycoprotein and is well known to interact with not only various ECM proteins and glycosaminoglycans such as collagen, gelatin $(\mathrm{G})$, heparin (Hep) and fibrin, but also the integrin receptor on the cell membrane (Figure 1b). ${ }^{40}$ Furthermore, FN has an important role in cell adhesion, migration, proliferation and differentiation. ${ }^{3}$ We have reported for the first time that ECM LbL multilayers focused on FN using biologically specific recognition. ${ }^{41}$ Various FN-based LbL multilayers using $G$ and $\alpha$-elastin (E) as an ECM protein, Hep and dextran sulfate (DS) as a glycosaminoglycan or its derivative, and $\alpha$-poly(L-lysine) ( $\alpha$-Lys) as a cationic polymer were fabricated using both electrostatic interaction and FN biological recognition. ${ }^{41,42}$ Although G, E, Hep and DS have a negative charge under physiological conditions, they interacted with negatively charged FN (pI 5.4) because FN has a binding domain for each component (biological recognition), for example, the dissociation constant $\left(K_{\mathrm{d}}\right)$ of $\mathrm{FN}-\mathrm{G}$ is approximately $0.6-5.0 \times 10^{-6} \mathrm{M}^{40,43}$ On the other hand, FN- $\alpha$-Lys and $\alpha$-Lys-DS (control) PE multilayers were also obtained through the conventional electrostatic interaction. A comparative evaluation between the FN-specific and electrostatic assembly was performed because we are especially interested in the difference in the driving forces for LbL assembly. The biodegradability and stability of ultrathin polymer films is one of the most important requirements for biomedical applications. Thus, we compared the enzymatic degradation and

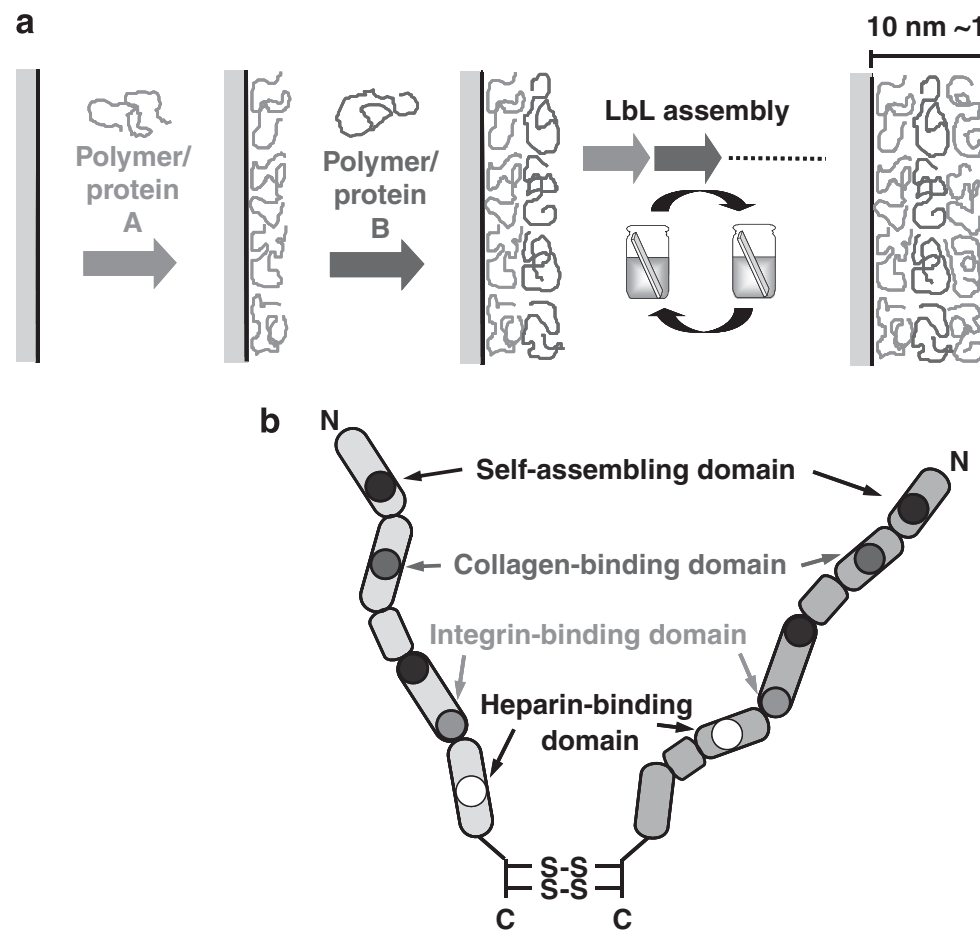

Figure 1 Schematic representations of (a) layer-by-layer (LbL) assembly and (b) dimer structure of fibronectin (FN). A full color version of this figure is available at Polymer Journal online. 
stability as biological properties of these two types of FN-based nanofilms.

Figure 2 presents the results of the LbL assembly and enzymatic degradation behaviors. Here, we chose elastase because it is well known as a serine protease possessing the characteristic ability to degrade FN within a short time at $37{ }^{\circ} \mathrm{C} .{ }^{44}$ Notably, the FN-DS films with larger thickness exhibited more rapid degradation behavior compared with that of the FN- $\alpha$-Lys films. It appears that the inhibition of the FN active site from additional DS was minimized because the excess adsorption of DS onto the FN layer was inhibited by electric repulsion. Tassel and coworkers ${ }^{45}$ also reported that the active sites of FN on poly(sodium styrenesulfonate)-terminated films were significantly more accessible compared with the poly(allylamine hydrochloride)-terminated films. These authors stated that the end segments of FN carry strong negative charges, whereas the middle segment is almost neutral; therefore, these researchers suppose that on a negatively charged surface, FN would adsorb in a side-on orientation. The excess adsorbed cationic $\alpha$-Lys on the FN layer may have inhibited the elastase access and activity.

The weight remaining percentage of the FN-G, FN-DS, FN- $\alpha$-Lys and $\alpha$-Lys-DS films in Eagle's minimum essential medium with $10 \%$ fetal bovine serum was evaluated at $37^{\circ} \mathrm{C}$. The FN-specific assembly films, FN-G and FN-DS (biological recognition), were surprisingly stable in the cell culture medium for $>150 \mathrm{~min}$, although the PE nanofilms (FN- $\alpha$-Lys and $\alpha$-Lys-DS) exhibited a weight increase in the first $15 \mathrm{~min}$. Thereafter, the weight gradually decreased. These results clearly show that FN-specific assembly films are more stable and useful for cell culture media. We hypothesized that some serum proteins in the culture medium adsorbed onto the PE film surfaces by electrostatic interactions in the first $15 \mathrm{~min}$, and protein exchange or desorption subsequently occurred.

These results clearly suggest that the driving force strongly affected the thickness, enzyme access or activity, and stability in culture medium. Biological recognition would induce a biologically adequate molecular structure of these films to maintain the functions of FN.

\section{COMFORTABLE MICROENVIRONMENTS TO CELLS BY FN-BASED MULTILAYERS}

A few reports on the preparation of nanometer-sized LbL multilayers on the surface of adhered cells have been published previously. Rajagopalan et al. ${ }^{46}$ fabricated a bilayer structure composed of hepatocytes and other cells by preparing a PE multilayer consisting of chitosan and DNA onto the hepatocyte surface. However, chitosan cannot dissolve in neutral buffer, and the use of PE films as a cell-adhesive material is limited because of the cytotoxicity of polycations. $^{29,47}$ The appropriate selection of natural ECM components for the preparation of the nanofilms is important to avoid cytotoxicity. Thus, the FN-based nanofilms constructed through the biological recognition driving force are expected to provide a cytocompatible microenvironment similar to the natural ECM.

Figure 3 shows the morphologies of mouse L929 fibroblasts after preparing the FN-based and PE multilayers. ${ }^{48,49}$ Table 1 summarizes the detailed information of the LbL assemblies. The PE multilayers
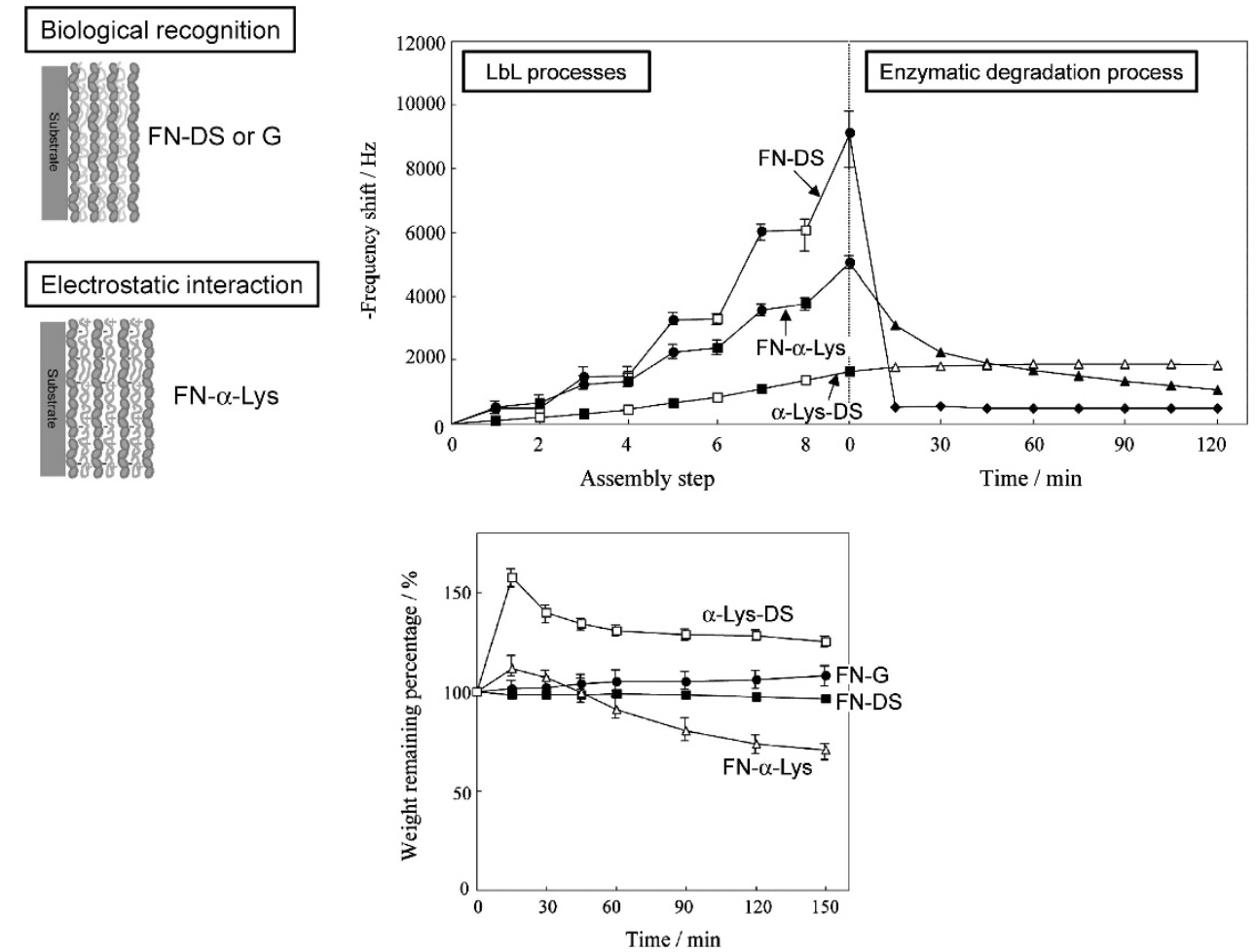

Figure 2 Top: frequency shift of the QCM stepwise assembly of FN (closed circle)-DS (open square), FN (closed circle)- $\alpha$-Lys (closed square) and $\alpha$-Lys (closed square)-DS (open square) in $50 \mathrm{~mm} \mathrm{~PB} \mathrm{(pH} \mathrm{7.4)} \mathrm{at} 37^{\circ} \mathrm{C}(n=3)$. Enzymatic degradation of FN-DS (closed diamond), FN- $\alpha$-Lys (closed triangle) and $\alpha$-Lys-DS (open triangle) films in aqueous solution with elastase at $37^{\circ} \mathrm{C}$ analyzed by QCM. $\alpha$-Lys-DS multilayers are a control sample of electrostatic assembly. Bottom: weight remaining percentage of nine-step assembled FN-G (closed circle), FN-DS (closed square), FN- $\alpha$-Lys (open triangle) and $\alpha$-Lys-DS (open square) films in Eagle's MEM with $10 \% \mathrm{FBS}$ at $37^{\circ} \mathrm{C}$ for $150 \mathrm{~min}(n=3)$. Reproduced with permission. ${ }^{40} \mathrm{FBS}$, fetal bovine serum; FN, fibronectin; DS, dextran sulfate; $\alpha$-Lys, $\alpha$-poly(L-lysine); MEM, minimum essential medium; PB, phosphate buffer; QCM, quartz crystal microbalance. A full color version of this figure is available at Polymer Journal online. 

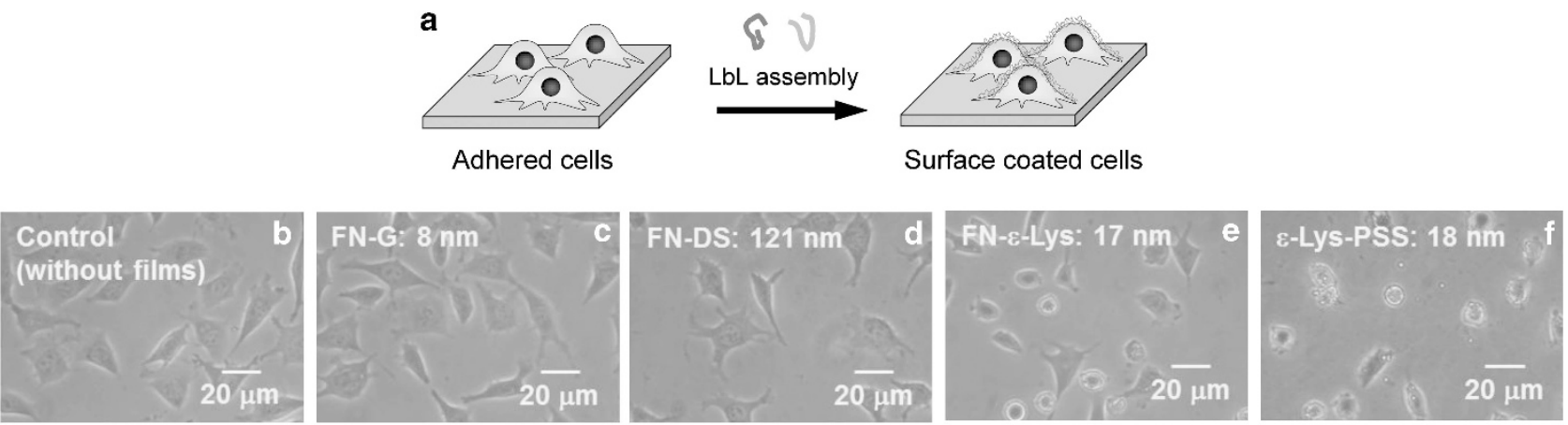

g

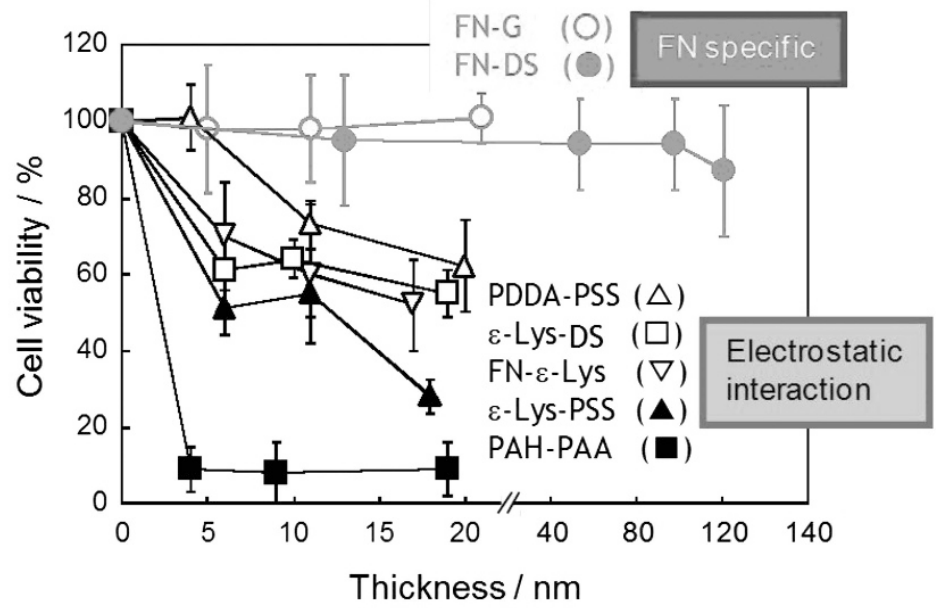

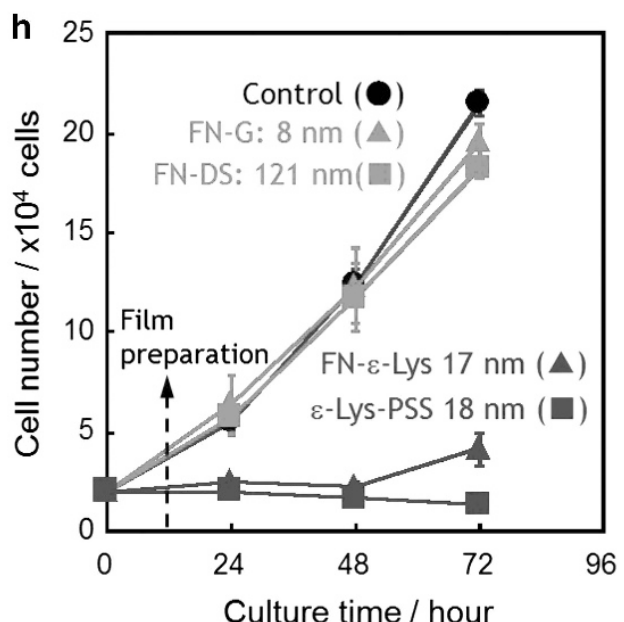

Figure 3 (a) Schematic illustration of layer-by-layer (LbL) assembly on adhered cell surfaces. (b-f) Phase contrast (Ph) images of the L929 fibroblasts (b) without or with (c) 8-nm-thick fibronectin (FN)-gelatin (G), (d) 121-nm-thick FN-dextran sulfate (DS), (e) 17-nm-thick FN- $\varepsilon$-Lys and (f) 18-nm-thick $\varepsilon$-Lyspoly(sodium styrenesulfonate) (PSS) nanofilms on the cell surfaces after $24 \mathrm{~h}$ of incubation. DS and $\varepsilon$-Lys represent sodium DS and $\varepsilon$-poly(lysine hydrochloride), respectively. (g) The relationship between cell viability and thickness of various nanofilms prepared on the cell surfaces after $24 \mathrm{~h}$ of incubation $(n=3)$. PAH and PAA represent poly(allylamine hydrochloride) and poly(acrylic acid), respectively. (h) Cell proliferation versus various nanofilms prepared on the $L 929$ cell surfaces during $72 \mathrm{~h}$ of incubation. Reproduced with permission. ${ }^{48} \mathrm{~A}$ full color version of this figure is available at Polymer Journal online.

induced a round-shaped morphology of the adhered cells, whereas each component of the multilayers had high cytocompatibility. On the other hand, the FN-G and FN-DS multilayers prepared by FNspecific interaction exhibited extended morphologies of the cells similar to that of the control cells (without films). Figure $3 \mathrm{~g}$ illustrates the relationship between cell viability and the thickness of the LbL films. An extremely high cell viability independent of the thickness of FN-based multilayers was observed even for the thickest 121-nm FNDS films, while all of the PE films exhibited thickness-dependent cytotoxicity. Furthermore, a clear difference in cell proliferation was observed for the PE and FN-based multilayers (Figure 3h). The cells with FN-based multilayers on their surfaces exhibited good proliferation profiles independent of the film thickness; however, cell growth was not observed using the PE multilayers, although the cells survived during the culture period. The morphologies of the FN-based and $\mathrm{PE}$ multilayers on the cell surface were examined by fluorescence microscopy and scanning electron microscopy. The nanometer-sized meshwork morphology of the FN-based multilayers on the cell surface was observed after $24 \mathrm{~h}$ of incubation, whereas the PE multilayers exhibited homogeneous film morphologies on the cell surface. ${ }^{48}$ The nano-meshwork morphologies were similar to the fibrous structure of the natural ECM.

To understand in detail the effect of PE films on cell functions, the secretion of interleukin-6 (IL-6) cytokine, which was expressed by the inflamed cells, was evaluated after preparing PE or FN-based multilayers (Figure 4). ${ }^{50}$ For the PE films, human normal dermal fibroblasts (NHDFs) expressed approximately 2.5-fold higher IL-6 per single cell compared with the NHDFs without films. On the other hand, the FN-based multilayers did not affect IL-6 production. Notably, FN-based multilayers with thicknesses $>50 \mathrm{~nm}$ successfully suppressed IL-6 secretion compared with the control cells. These results suggest that the PE films prepared on the cell surface induce strong inflammation to the cells, most likely due to the cationic cytotoxicity. Finally, the films would induce cell death or growth arrest depending on the thickness, cationic charge or cationic species. In contrast, the FN-based nanofilms provided cytocompatible extracellular microenvironments similar to the natural ECM, thus suppression of the inflammation cytokine IL-6 was observed.

These results suggest that the FN-based multilayers directly prepared on cell surfaces can act as a bio-mimetic ECM for providing a comfortable microenvironment to the cells.

\section{PROTECTION PROPERTY OF FN-BASED MULTILAYERS FROM PHYSICAL STRESS}

To understand additional effects of the FN-based multilayers coated on cell surfaces, we focused on the protection properties of the multilayers for the cell membrane because cells recently are affected by various stresses from physical, chemical and environmental stimuli for 
Table 1 Summary of the FN-based and PE multilayers components and cell types used in this paper

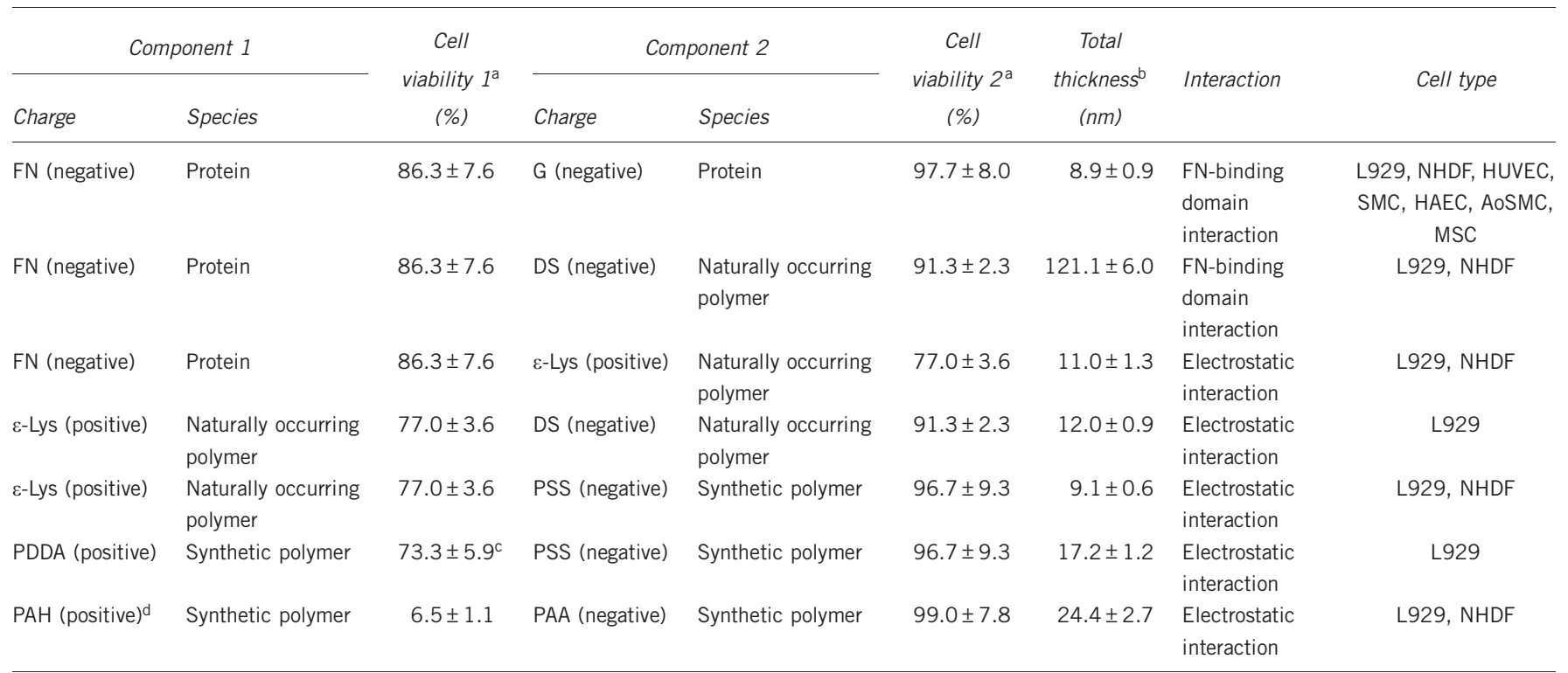

Abbreviations: AoSMC, human aortic smooth muscle cell; DS, sodium dextran sulfate; e-Lys, e-poly(lysine hydrochloride); FN, fibronectin; G, gelatin; HAEC, human artery endothelial cell; HUVEC, human umbilical vein endothelial cell; L929, mouse L929 fibroblast; LbL, layer-by-layer; MSC, mesenchymal stem cell; NHDF, normal human dermal fibroblast; PAA, poly(acrylic acid); PAH, poly(allylamine hydrochloride); PDDA, poly(diallyldimethylammonium chloride); PE, polyelectrolyte; PSS, poly(sodium styrenesulfonate); SMC, smooth muscle cell. Concentration of each solution used for $\mathrm{LbL}$ assembly is $0.2 \mathrm{mg} \mathrm{ml}^{-1}$ in $50 \mathrm{~mm}$ Tris- $\mathrm{HCl}(\mathrm{pH}=7.4)$.

The living cell percentage was estimated from positive control sample as $100 \%$, which was not performed in any treatment. Reproduced with permission. ${ }^{48}$

aCell viability was determined after immersion in $0.2 \mathrm{mg} \mathrm{ml}^{-1}$ of each component solution for $15 \mathrm{~min}$ by using WST-1 reagent (Dojindo Co. Ltd, Kumamoto, Japan).

bThe total thickness at 13 step on a phospholipid bilayer prepared on $2.3 \pm 0.4 \mathrm{~nm}$ of (PDDA-PSS) 1.5 base layer is $4.1 \pm 1.1 \mathrm{~nm}$.

${ }^{c}$ Concentration of PDDA solution is $0.02 \mathrm{mg} \mathrm{ml}^{-1}$ in $50 \mathrm{~mm}$ Tris- $\mathrm{HCl}(\mathrm{pH}=7.4)$ with $0.035 \mathrm{M} \mathrm{CaCl}_{2}$.

dPAH is a negative control as a cytotoxic component.
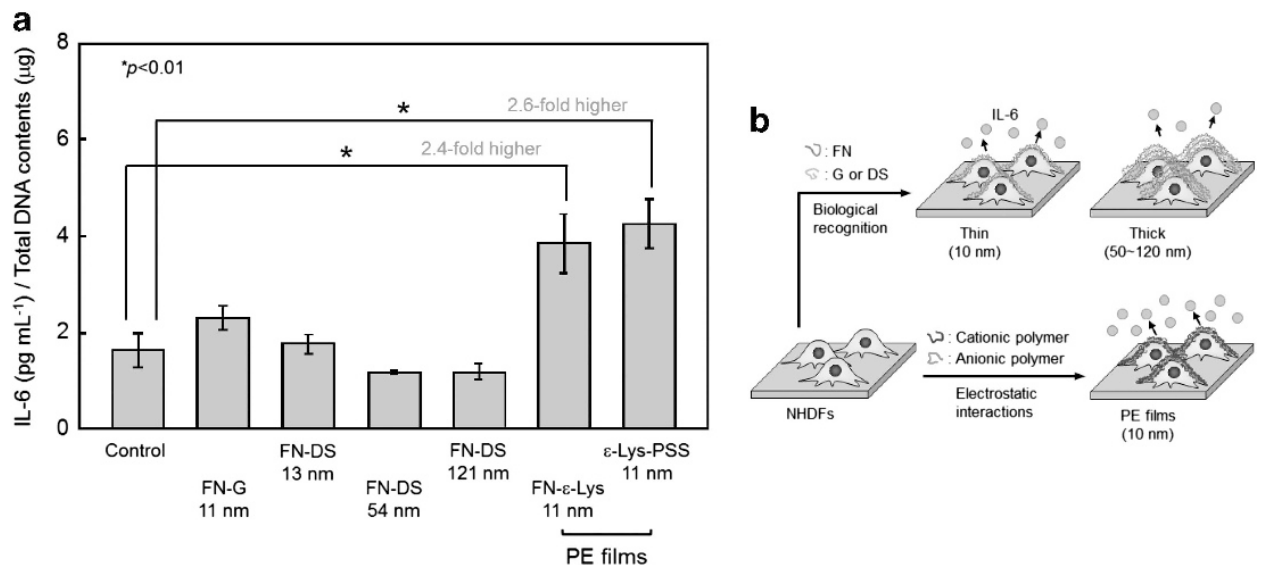

Figure 4 (a) Interleukin-6 (IL-6) secretion versus the DNA amount of human normal dermal fibroblasts (NHDFs) without or with fibronectin (FN)-based (FNgelatin (G) and FN-dextran sulfate (DS)) or polyelectrolyte (PE) films on the cell surfaces after $24 \mathrm{~h}$ of incubation $(n=3)$. (b) Schematic representation of IL-6 expression from NHDFs with thin or thick FN-based multilayers and PE films. An asterisk denotes a statistically significant difference using a two sample $t$-test $\left({ }^{*} P<0.01\right)$ for each comparison. Reproduced with permission. ${ }^{49} \mathrm{~A}$ full color version of this figure is available at Polymer Journal online.

biological, biomedical and tissue engineering applications. For example, Boland and coworkers ${ }^{51}$ reported the formation of nanometer-sized pores on cell membranes because of shear stress during the inkjet printing process. Accordingly, we must carefully consider cell viability and function during tissue engineering processes. As the coating of LbL assembled nanofilms onto floating cell membranes requires many cycles of centrifugation (Figure $5 \mathrm{a}$ ), ${ }^{30}$ the physical stress may damage the cell membranes, causing the leakage of cytosol molecules or ultimately cell death. However, there are no reports on physical stress during LbL assembly processes.

We investigated for the first time the effect of LbL assembly centrifugation processes (gravity stress) on cell viability and the leakage of cytosol enzymes. ${ }^{52}$ After two steps of LbL assembly using Tris-HCl buffer solution without polymers or proteins (four centrifugation cycles including washing), hepatocyte carcinoma (HepG2) cells exhibited extremely high cell death and viability was approximately $15 \%$ (Figure 5 ). Their viability ultimately decreased to $6 \%$ after nine-step LbL assembly (18 cycles of centrifugation), which is the typical number of steps involved in preparing LbL nanofilms. On the other hand, significantly higher viability ( $>85 \%$ ) of HepG2 cells was obtained after nine-step LbL assembly using FN-G or type IV collagen (Col IV)-laminin solution combinations, which are typical components of the ECM, to fabricate 10-nm-thick LbL films. When LbL films of synthetic polymers created via electrostatic 
a
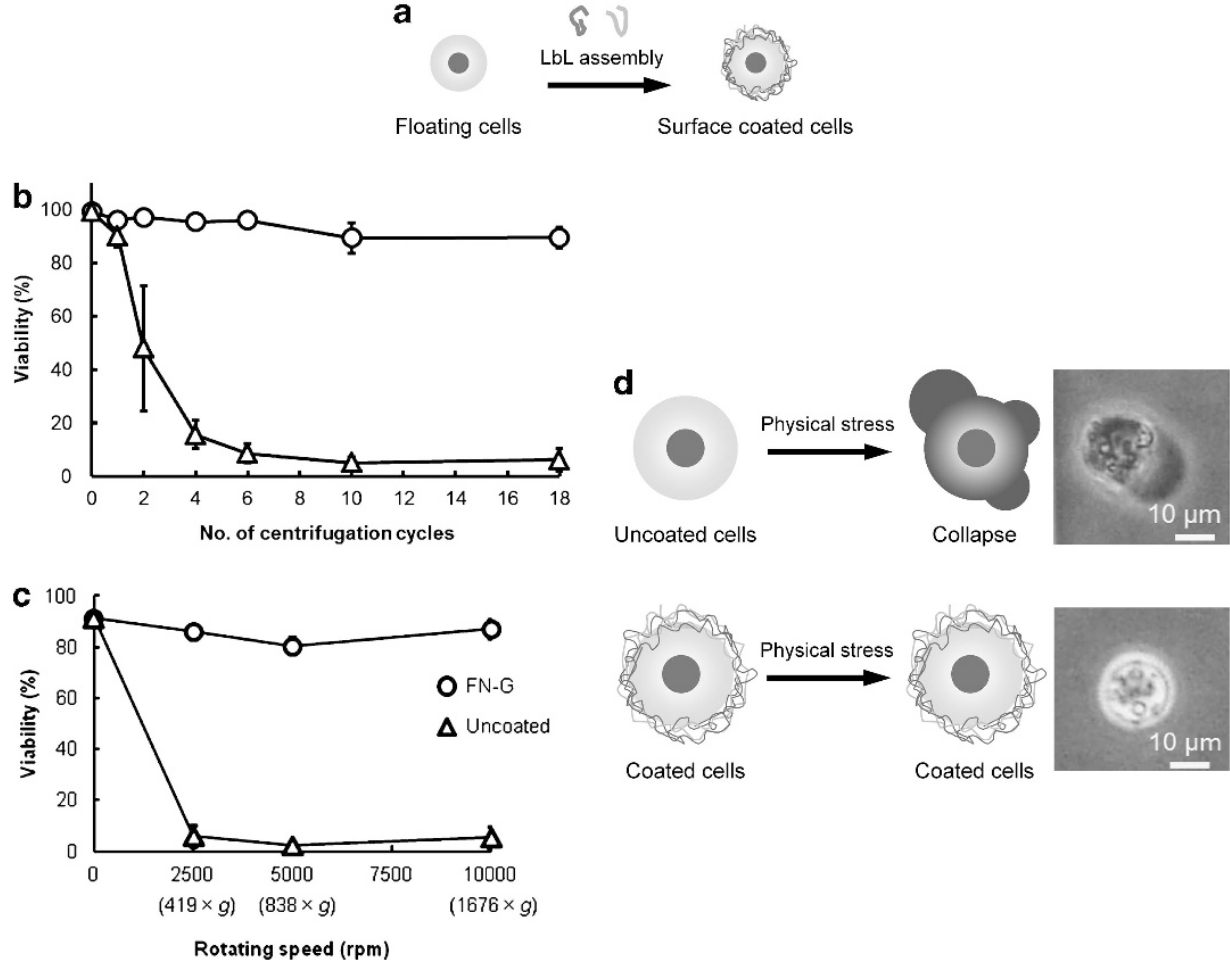

Figure 5 (a) Schematic representation of layer-by-layer (LbL) assembly on floating cell surfaces. (b) Cell viability of HepG2 cells (circle) with or (triangle) without fibronectin (FN)- gelatin (G) multilayers for nine-step LbL assembly $(n=3)$. (c) The viability of HepG2 cells with FN-G nanofilms after nine-step LbL assembly and uncoated cells that underwent the same centrifugation regime was measured at various rotation speeds $(n=3)$. The viability was calculated using the ratio of the number of living cells to the total number of cells. (d) Schematic illustration of the effect of physical stress on uncoated or coated cells with FN-based multilayers. Reproduced with permission. ${ }^{51}$ A full color version of this figure is available at Polymer Journal online.

interactions were used instead of the ECM films described above, the viability of the HepG2 cells after the same nine steps slightly decreased to $61 \%$. The protective effects of the LbL films were strongly dependent on their thickness, and the critical thickness was $>5 \mathrm{~nm}$. Surprisingly, high viability $>85 \%$ was achieved even under extreme physical stress conditions (10000 r.p.m.). We evaluated the leakage of lactate dehydrogenase during the $\mathrm{LbL}$ assembly processes to clarify the protective effect, and a reduction in lactate dehydrogenase leakage was clearly observed when using the FN-G nanofilms. Moreover, the LbL films do not inhibit cell growth during cell culture, suggesting that these coated cells may be useful for other experiments.

These results show that LbL nanofilm coatings, especially ECM nanofilm coatings, will be important techniques for protecting cell membranes from physical stress during tissue engineering.

\section{HIERARCHICAL CELL MANIPULATION TECHNIQUE}

Quantitative and time-lapse analyses in microenvironments for drug diffusion, drug toxicity and the release of molecules from drug delivery carriers are useful to explore the physiological processes, mechanisms and treatments of disease or injury through pathophysiology. Various spatial analytical instruments such as computed tomography, magnetic resonance imaging and positron emission tomography have been used for general in vivo animal experiments in pathophysiology. However, although their detection limits have continually improved, the detection of events on the micrometer scale remains difficult. Moreover, species differences between animals and humans can cause fundamental confounders such as metabolic processes, enzymes and membrane proteins. Accordingly, in vitro human cell-based drug evaluations, including drug efficacy testing, toxicology and basic cell biology, ${ }^{53,54}$ are of great importance as an alternative to animal experiments to overcome the significant issue of species differences. In particular, animal testing for cosmetics and chemicals has been prohibited under the 7th Amendment to the Cosmetics Directive (Council Directive 76/768/EEC) and REACH (registration, evaluation, authorization and restriction of chemicals) in the European Union since March 2013. ${ }^{55}$ Cell-based drug evaluations have generally been performed in a plastic dish under monolayer (2D) cell conditions. As nearly all tissues are integrated 3D structures of multiple types of cells and ECMs, and because intercellular signaling is important for biological functions, it is generally difficult to estimate the actual drug effects on physiologic functions using 2D culture methods. The development of 3D human tissue constructs consisting of simplified tissue structures with multiple types of cells and ECMs is a key challenge for pharmaceutical and pathophysiological evaluations and tissue engineering.

A cell spheroid has been generally used as the 3D culture model, especially $3 \mathrm{D}$ cancer spheroids for metastasis or pharmacological assays of cancer cells ${ }^{56-58}$ and $3 \mathrm{D}$ hepatocyte spheroids for inducing higher activity of hepatocytes. ${ }^{59,60}$ Although interesting $3 \mathrm{D}$ co-culture spheroids have been reported to investigate tumor invasion, ${ }^{61,62}$ enhance hepatocyte functions ${ }^{63}$ and mimic in vivo conditions, ${ }^{64}$ the reconstruction of the delicate and precise $3 \mathrm{D}$ location of multiple types of cells has not yet been achieved because of their heterogeneity, the lack of control of the cell number and location, and necrosis inside the cells because of insufficient nutrients.

In general cell culture, the cells proliferate on appropriate substrates in growth media to reach a confluent condition, and the cells stop their growth because of contact inhibition. Thus, it has been difficult to obtain 3D-multilayered tissues under normal conditions. 
Moreover, even if the cells were seeded onto adhered cells, they did not adhere and organize completely because of the lack of an ECM on the cell surfaces and electrostatic repulsion between the cells. We assumed that if the direct fabrication of nanometer-sized cell-adhesive materials such as ECM fibrous scaffolds onto the surface of a cell membrane is possible, then the cells seeded as the second layer may be able to recognize the adhesion substrates and adhere onto the first monolayered cells to generate bilayer structures. Repeating this process would yield 3D-multilayered structures in vitro, and we call this technique 'hierarchical cell manipulation' (Figure 6). ${ }^{49,65}$ The FN-based multilayers, especially FN-G nanofilms, were selected as the nano-ECM film because as mentioned before, FN can interact not only with various ECM proteins such as collagen (G) and glycosaminoglycan, but also with the $\alpha_{5} \beta_{1}$ integrin receptor on the cell surface. Thus, FN-G nanofilms are expected to serve as an artificial nano-ECM scaffold to fabricate 3D-multilayered tissues by providing a suitable cell-adhesive surface similar to the natural ECM without any cytotoxicity. Using FN-G nanofilms on the cell surface, the in vitro fabrication of 3D-multilayered tissues can be achieved.

We fabricated a bilayer of mouse L929 fibroblast cells with or without FN-G nanofilms using a cover glass as the substrate. When the seven-step assembled FN-G nanofilms (thickness is $6.2 \mathrm{~nm}$ ) were prepared on the surface of the first L929 cell layer, the second layer cells were then observed on the first cell layer. However, when the nanofilm was not prepared or the one-step-assembled nanofilm (only $\mathrm{FN}$, thickness is $2.3 \mathrm{~nm}$ ) was assembled on the first cell layer, then the bilayer architecture was not observed. These results suggested that $2.3 \mathrm{~nm}$ of FN film was inadequate and that at least approximately $6 \mathrm{~nm}$ of the FN-G nanofilm was required as a stable adhesive surface for the second cell layer. The four-layered $(4 \mathrm{~L})$ cellular multilayers were clearly observed after four repetitions of these steps by confocal laser scanning microscopy (CLSM) and hematoxylin and eosin- staining images (Figure 7). The thickness of the obtained multilayers estimated from 3D-reconstructed CLSM images linearly increased with increasing cell layer number. This hierarchical cell manipulation technique can be applied to various types of cells, for example, myoblast cells, cardiac myocytes, smooth muscle cells (SMCs), hepatocytes (Hep) and endothelial cells (ECs). The FN-G nanofilms did not exhibit any cytotoxicity, and the obtained 3D cell architectures exhibited high intercellular adhesion and easily peeled off from the substrate (Figure 7f).

\section{HIGH CELLULAR FUNCTIONS INDUCED BY 3D ARCHITECTURES}

Studies on the functions of layered cellular architectures compared with a cell monolayer (1L) are valuable not only for understanding how a 3D environment composed of cells, ECM, and signaling molecules regulates functions similar to natural tissues but also for creating 3D artificial tissues resembling natural tissues. Recently, some researchers have reported the functions of layered cellular architectures in vitro. ${ }^{66-68}$ However, the basic properties induced by $3 \mathrm{D}$ cellular structures, such as the layer number or the cell types, have not yet been clarified. We evaluated the structural stability of layered constructs consisting of NHDFs and human umbilical vein ECs (HUVECs) in relation to their layer number. ${ }^{69}$ The two types of layered constructs, 1L-NHDF/1L-HUVEC and 4L-NHDF/1LHUVEC, were prepared using approximately $6 \mathrm{~nm}$ of FN-G nanofilms. To evaluate the general effects of the 3D-layered structures on cellular stress or inflammation, we purposely fabricated biologically meaningless layered structures consisting of ECs and fibroblasts.

Notably, the HUVECs adhered homogeneously on the surface of the $4 \mathrm{~L}$ NHDFs, and tight-junction formation was widely observed at the centimeter scale, while heterogeneous HUVEC domain structures were observed on the monolayered (1L) NHDFs (Figure 8). The

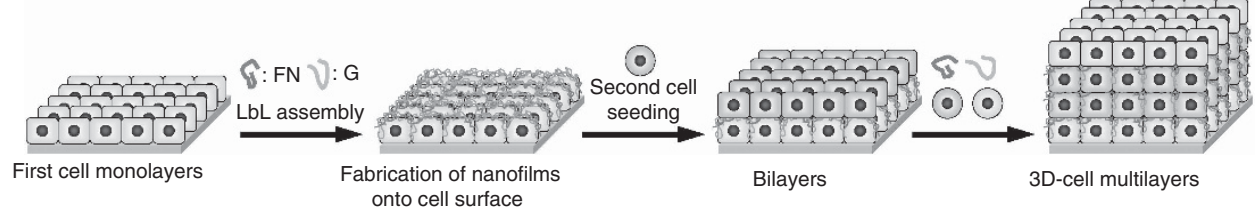

Figure 6 Schematic illustration of hierarchical cell manipulation technique. A full color version of this figure is available at Polymer Journal online.
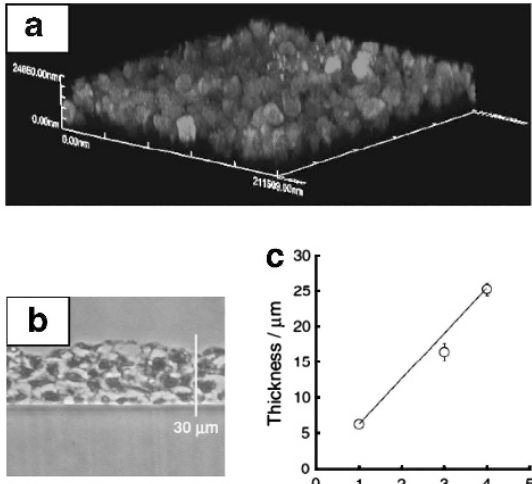

d
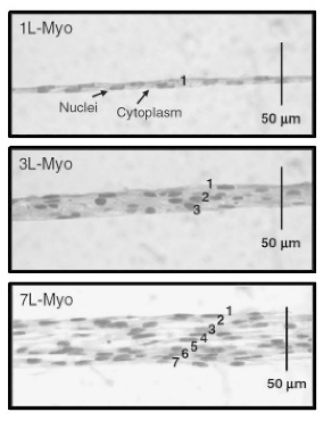

e
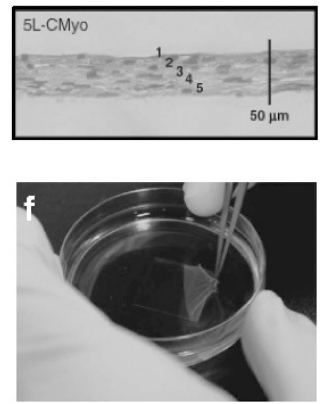

Figure 7 (a) Three-dimensional (3D)-reconstructed confocal laser scanning microscopy (CLSM) cross-sectional image of four-layered (4L) L929 cells. The cells were labeled with cell tracker green. (b) Hematoxylin and eosin (HE) staining image of 4L L929 cells. (c) Relationship between the L929 cell layer number and the mean thickness estimated from 3D CLSM images $(n=3)$. (d) HE staining images of 1-, 3- and 7L mouse C2C12 myoblast cells (Myo). (e) HE image of $5 \mathrm{~L}$ rat cardiac myocytes (CMyo). (f) Photograph of the peeling process of $4 \mathrm{~L}$ L929 cells from a coverglass as the substrate. Reproduced with permission. ${ }^{48} \mathrm{~A}$ full color version of this figure is available at Polymer Journal online. 

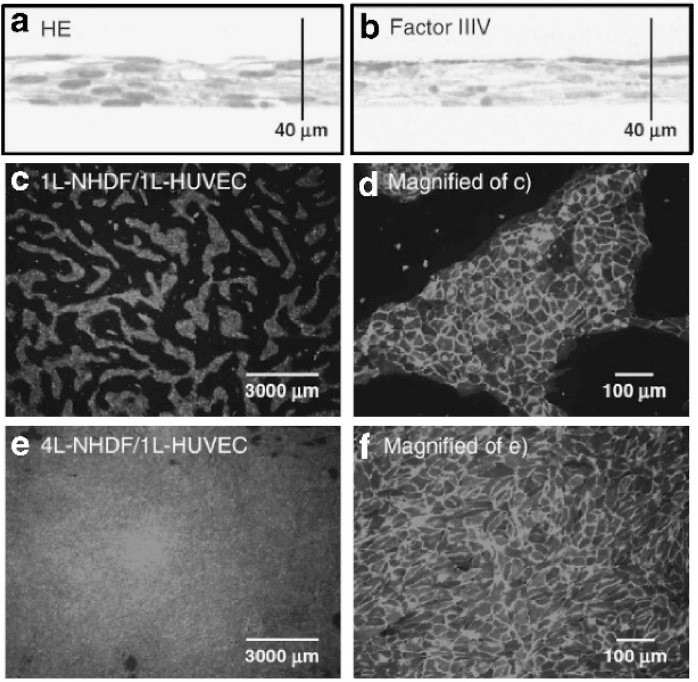

g

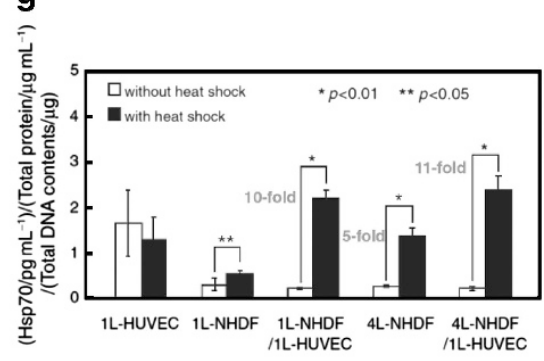

h

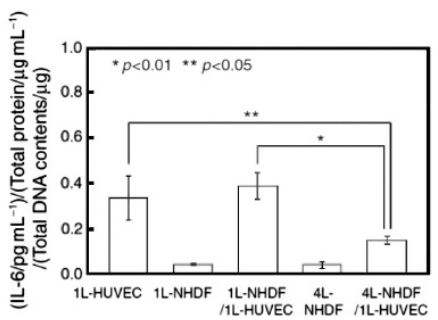

Figure 8 Histological images of four-layered (4L) human normal dermal fibroblast (NHDF)/1L human umbilical vein endothelial cell (HUVEC) constructs stained for: (a) hematoxylin and eosin (HE) and (b) factor VIII. Fluorescent immunostaining images of (c, d) $1 \mathrm{~L}$ NHDF/1L HUVEC and (e, f) 4L NHDF/1LHUVEC constructs immunostained with an anti-CD31 antibody (g). Production of heat shock protein 70 (Hsp70) versus total protein from non-heat-shocked and heat-shocked layered constructs composed of NHDFs and HUVECs $(n=4)$. The heat shock conditions were 20 min incubation at $45^{\circ} \mathrm{C}$, followed by a 2-h recovery period. (h) Interleukin-6 (IL-6) secretion versus total protein from the layered structures $(n=3)$. Asterisk denotes a statistically significant difference using a two-sample $t$-test $\left({ }^{*} P<0.01,{ }^{*} P<0.05\right)$ for each comparison. Reproduced with permission. ${ }^{65} \mathrm{~A}$ full color version of this figure is available at Polymer Journal online.

production of heat shock protein 70 and IL-6 from the cellular structures were investigated to elucidate any $3 \mathrm{D}$ structural effect on cellular function. The heat shock protein 70 expression of the HUVECs decreased after adhesion onto the 4L NHDF structure compared with the HUVEC monolayer. Surprisingly, the heat shock protein 70 production response to heat shock increased drastically by approximately 10 -fold compared with non-heat shock by 3D structure formation, whereas the monolayer structures exhibited no change. Moreover, the production of the inflammatory cytokine IL6 decreased significantly depending on the layer number of NHDFs. These results suggested that $4 \mathrm{~L}$ NHDF provided a more favorable environment for HUVECs than a cell culture plastic disk to induce high thermosensitivity and to suppress the inflammatory response from the substrate. The microenvironment of a cell surface covered with FN-G films similar to ECMs would be an analogous condition to natural tissues compared with the plastic disk. These findings could be important not only for tissue engineering but also for basic cell biology.

\section{D BLOOD VESSEL WALL MODELS FOR IN VITRO ANALYSIS OF DRUG RESPONSES}

In physiology and medicine, blood vessels are relevant not only for circulatory diseases and treatments but also for the biological evaluation of drug diffusion to target tissues, the penetration of cancer cells or pathogens, and the control of blood pressure. A blood vessel is generally composed of three distinct layers: the intima, an inner single layer of ECs; the media, medium layers of SMCs; and the adventitia, an outer layer of fibroblast cells. The nitric oxide (NO) produced from ECs diffuses into SMCs through their cell membranes and activates guanylate cyclase to produce intracellular cyclic guanosine monophosphate, which induces a signaling pathway mediated by kinase proteins leading to SMC relaxation. ${ }^{70}$ Accordingly, quantitative, kinetic and spatial analyses of the extracellular delivery of NO molecules from the EC layer to the SMC layers upon drug stimulation are crucial for pharmaceutical and biomedical evaluations of hypertension and diabetes. Recently, a significant correlation between NO production and diabetes mellitus was clarified, for example, reduced NO production in both type 1 and 2 diabetes ${ }^{71,72}$ and an increase of NO production related to the improvement of type 2 diabetes were reported. ${ }^{73}$ Thus far, pharmaceutical assays of NO production have been performed using in vivo animal experiments; however, low reproducibility and different NO production depending on animal types remain unsolved issues. Thus, the development of a convenient and versatile method for the in vitro quantitative and spatial analyses of NO diffusion inside the artery wall instead of animal experiments is important for biological and pharmaceutical applications.

We reported biocompatible and highly sensitive NO sensor particles (SPs) prepared by LbL assembly. Mesoporous, micrometersized silica particles encapsulating the 4,5-diaminofluorescein, NO fluorescent indicator dye, were covered with biocompatible chitosanDS LbL films to provide cytocompatibility and to inhibit leakage of the 4,5-diaminofluorescein. The NO SPs exhibited high NO-sensitivity at $5-500 \mathrm{~nm}$, which is sufficient to detect $\mathrm{NO}$ at concentrations of hundreds of nM (EC production level ${ }^{74}$ ). ${ }^{75}$ If an artificial 3D artery model allocating these SPs can be developed, the extracellular diffusion of NO from the EC layer to the SMC layers with chemical and physical stimuli is expected to be observed in vitro fluorescently using CLSM. We successfully developed 3D blood vessel models consisting of human ECs and SMCs, and their morphology and histology were evaluated in detail. ${ }^{76}$ The five-layered (5L) blood vessel models consisting of 4L SMC and an outermost 1L HUVEC resulted in histological staining images similar to those of the human aorta, and the surface of $4 \mathrm{~L}$ SMC/1L EC revealed high biocompatibility, avoiding adsorption and activation of platelets in human platelet-rich plasma. Herein, we combined both the SP technique and hierarchical cell manipulation to develop 5L artery models including SPs using human aortic smooth muscle cells (AoSMCs) and human aortic ECs (HAECs), as shown in Figure 9. ${ }^{77}$ 
To clarify the effect of the layered structure consisting of AoSMCs and HAECs on NO production, the NO concentrations from various 2D or 3D structures consisting of AoSMCs and HAECs prepared by FN-G nanofilms as described above after $48 \mathrm{~h}$ of culture were evaluated using a horseradish peroxidase assay. ${ }^{78}$ The NO production of the 1L HAECs was fourfold higher than that of the 1L AoSMCs, and the bilayer structure of HAECs with AoSMCs promoted a twofold higher NO production than the 1L HAECs.

Using SPs, the localized NO concentration around the HAECs could be analyzed quantitatively. It has been predicted that the NO concentration on the membrane surface may vary from submicroor micro-molar levels; ${ }^{79}$ however, distinct differences in $\mathrm{NO}$ concentration at various membrane positions have not yet been elucidated. Accordingly, we attempted to clarify the difference in NO concentration at the apical and basal membranes of 1L HAECs after the addition of bradykinin, which is an NO agonist peptide hormone, using SPs (Figure 10). When bradykinin was added to the culture medium, the NO concentration at the apical membrane (on the cells) rapidly increased to approximately $110 \%$ within $5 \mathrm{~min}$ and was subsequently stable over $2 \mathrm{~h}$. However, the NO concentration at the basal membrane (under the cells) also rapidly increased to $>140 \%$ and reached a stable value after $40 \mathrm{~min}$. These results suggest that NO production from the basal membrane is higher than that of the apical membrane. To evaluate the 3D structural effect of the cellular alignment on localized NO production, the NO concentration at the apical and basal membranes of the HAECs in monolayers or bilayers after $48 \mathrm{~h}$ of incubation was analyzed by the SPs. The NO concentrations at the basal membrane of the HAECs in the monolayer and bilayer were 4.5-fold and 2-fold higher, respectively, than those on the HAEC surfaces, suggesting that the NO molecule was more readily produced at the basal membrane than at the apical membrane independent of 3D-layered structure. Ortiz et al. ${ }^{80}$ recently reported that endothelial NO synthase was highly localized around the middle and basal sides of the ECs in the rat ascending limb. Thus, the amount of NO production at the basal membrane would be higher than that at the apical membrane.

We demonstrated a quantitative 3D analysis of $\mathrm{NO}$ diffusion from the uppermost $1 \mathrm{~L}$ HAECs to the underlying $4 \mathrm{~L}$ AoSMCs in $5 \mathrm{~L}$ artery models using the SPs. The SPs were allocated into each layer as shown in Figure 9. Figure 10b presents 3D-reconstructed CLSM images of the $5 \mathrm{~L}$ constructs after $48 \mathrm{~h}$ of culture, where the green and blue colors represent the SPs and nuclei, respectively. The averaged local NO concentrations in each layer were quantified from the cross-sectional image (Figure 10c) and are summarized in Figure 10d. The NO concentrations in the first (HAEC) and second (AoSMC) layers were approximately $530-550 \mathrm{~nm}$ and then gradually decreased with increasing layer number. The NO concentration reached approximately $50 \%$ (290 nM) in the fifth layer ( $32 \mu \mathrm{m}$ in depth). Furthermore, the distance of NO diffusion from the top HAEC layer to the underlying AoSMC layers was estimated to be approximately $60 \mu \mathrm{m}$ from the equation of NO diffusion distance obtained from Figure 10d. Although this value is slightly lower than the reported in vivo NO diffusion distance of approximately $100-200 \mu \mathrm{m},{ }^{79,81}$ the obtained value may be reasonable when considering the NO consumptions, both approximately $37 \%$, during chemical reactions in the artery walls ${ }^{81}$ and for the large amount of SPs in each layer. These results suggest that this technique will be a useful method for in vitro artery assays to replace in vivo animal experiments.

\section{CELL ACCUMULATION TECHNIQUE FOR VASCULARIZED 3D TISSUE CONSTRUCTION}

Although the hierarchical cell manipulation technique allows for exact layered structures with the desired cell types and ECM, it is difficult to generate thick 3D-layered tissues using this approach because a maximum of two layers per day was possible because of stable cell adhesion. Moreover, the introduction of vascular structures was not successful. To overcome the problem of this one-by-one method, we rapidly constructed thick $3 \mathrm{D}$ tissues using the nano-ECM coating of FN-G films onto single cells in dispersion, but not adhered cells, which we called the cell-accumulation technique (Figure 11). ${ }^{82}$ As FN$\mathrm{G}$ nanofilms prepared on individual cell surfaces exhibit an interactive property with the $\alpha_{5} \beta_{1}$ integrin receptor of the cell membrane, the cell-cell adhesion of all the seeded cells in three dimensions can be induced simultaneously (cell accumulation process).

We began with the formation of FN-G nanofilms onto single cells to confirm the homogeneity and stability of the FN-G nanofilms. The CLSM images demonstrated the successful preparation of FN-G nanofilms on the cell surfaces. The FN-G nanofilms did not affect

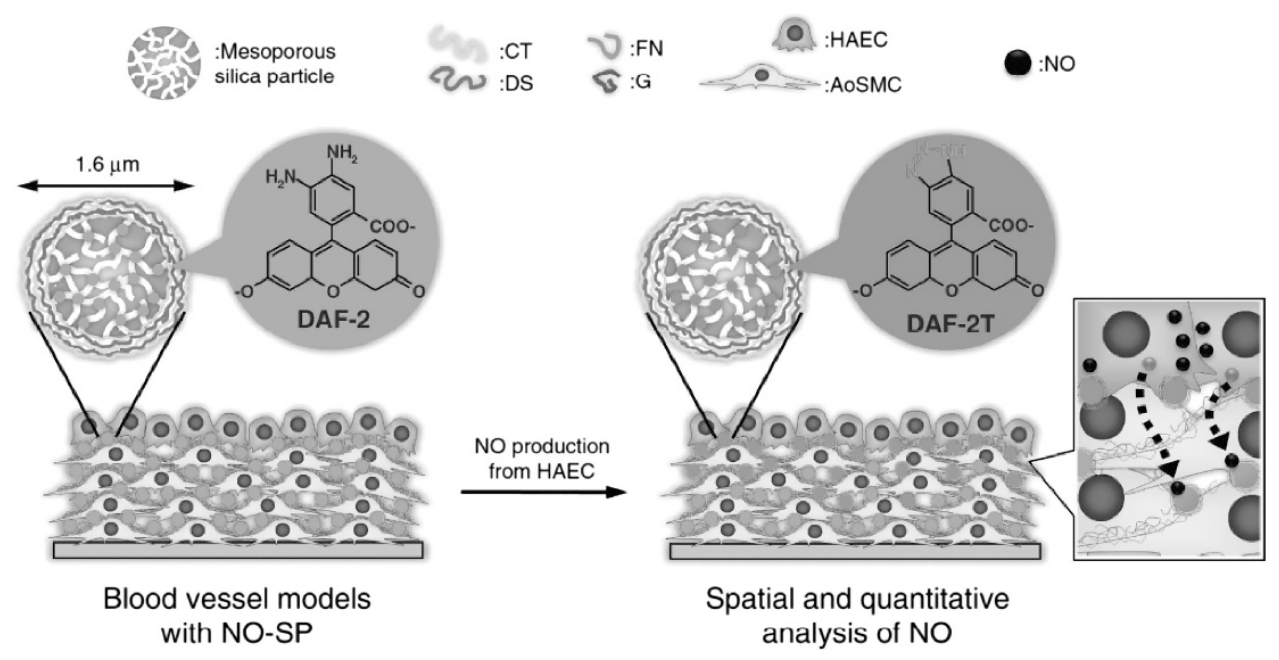

Figure 9 Schematic illustration of the in vitro spatial and quantitative analyses of nitric oxide (NO) diffusion from the uppermost human aortic endothelial cell (HAEC) layer to the human aortic smooth muscle cell (AoSMC) layers in a three-dimensional (3D) artery model using sensor particles (SPS). The SPs were homogeneously distributed within the 3D-layered blood vessel wall model. Reproduced with permission. ${ }^{76} \mathrm{~A}$ full color version of this figure is available at Polymer Journal online. 

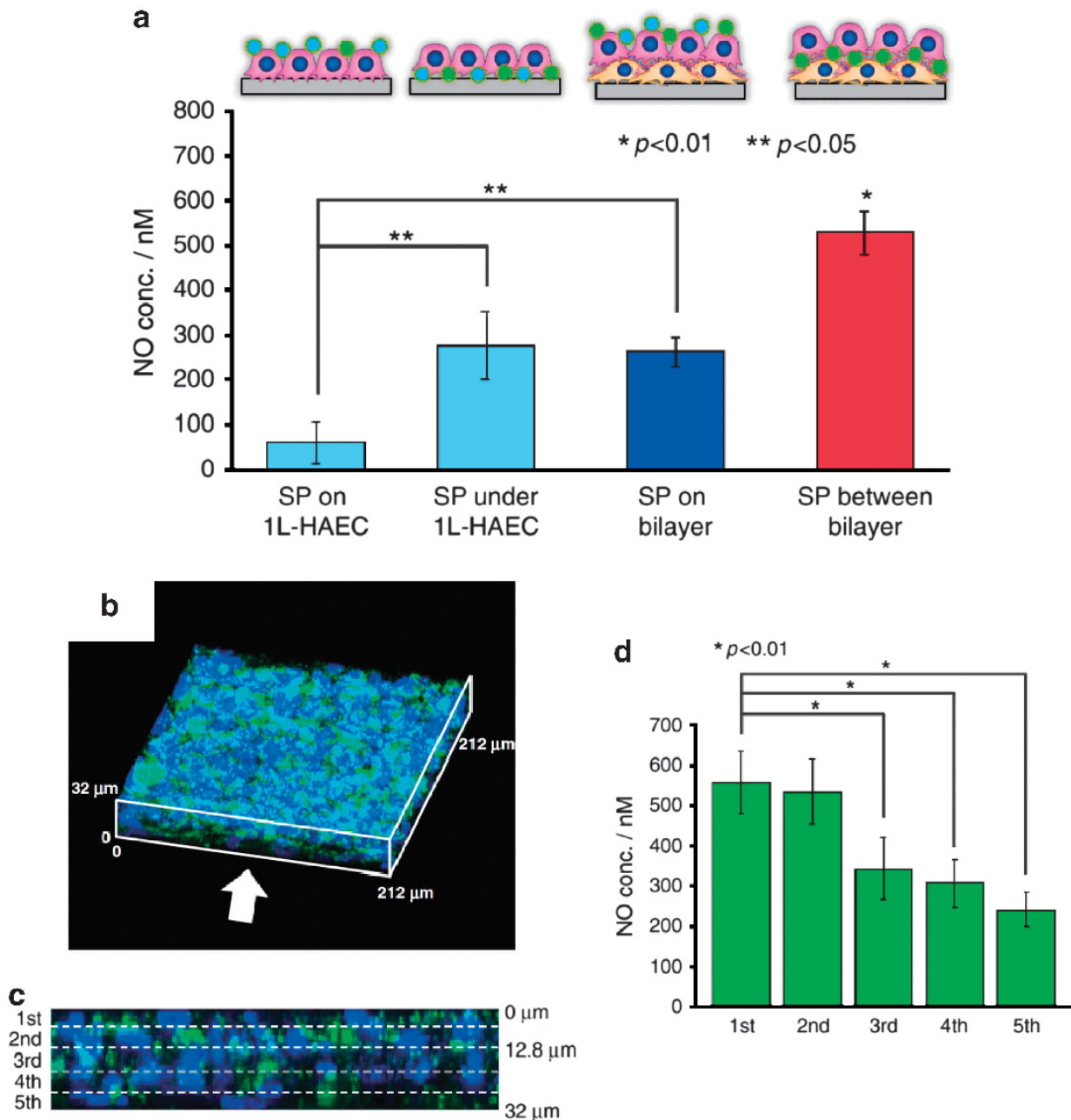

Figure 10 (a) Localized nitric oxide (NO) diffusion in relation to three-dimensional (3D) structural effects. The localized NO concentrations were analyzed by sensor particles (SPs) on and under the human aortic endothelial cells (HAECs) in monolayers and bilayers after $48 \mathrm{~h}$ of incubation. The mean fluorescence intensity of the SPs was measured from confocal laser scanning microscopy (CLSM) images ( $n=3$, over 20 SPs per image), and the NO concentration was estimated from a calibration curve. If: fluorescence intensity. (b) 3D-reconstructed CLSM image of a five-layered (5L) artery model containing SPs (green) in each layer after $48 \mathrm{~h}$ of incubation. The first layer is HAECs, and the second to fifth layers are human aortic smooth muscle cells (AoSMCs). (c) Cross-sectional CLSM image of (b) in the white arrow direction. The dashed lines represent the brief interfaces of each layer. (d) The localized NO concentrations in each cell layer were analyzed using the SPs. The fluorescence intensities of the SPs were measured from each layer in (c) ( $n=3$, over 20 SPs per image, ${ }^{* *} P<0.05,{ }^{*} P<0.01$ ). Reproduced with permission. ${ }^{76}$

fundamental cellular functions such as cell viability $(>98 \%)$ or proliferation, whereas other PE-based multilayer films exhibited higher cytotoxicity depending on the step number and thickness of the films as well as the results of the film formation on the adhered cell surfaces. To test whether FN-G nanofilms prepared onto single cells could function as an adhesion scaffold, cell accumulation was performed. The FN-G-coated cells adhered to each other and organized to form layered structures after 1 day of incubation. However, for cells without the ECM coating, many defects and detached cells were observed in the tissues. Moreover, we confirmed that the FN-G nanofilms transformed their morphologies from films to fibrous structures, similar to the natural ECM. These results suggest that FN-G nanofilms formed onto a single-cell functioned as a scaffold and promoted the organization of 3D tissues. More importantly, the construction of approximately 10 layers per day after only a nanofilm coating within $1 \mathrm{~h}$ has never been reported previously, and this approach has tremendous versatility for various cells such as human hepatocellular carcinoma (HepG2). One difference from hierarchical cell manipulation is the cell density. As the coated cells were seeded at once for 3D construction, the cell density of the cell accumulation technique is higher than that of the hierarchical cell manipulation.

To apply this cell-accumulation technique to the blood-capillary model, a sandwich culture method was used. HUVECs with FN-G nanofilms were seeded onto NHDF multilayers constructed using the cell-accumulation technique to obtain tissues with HUVEC layers on top. Next, FN-G-coated NHDFs were seeded onto the tissues again for the sandwich culture of HUVECs between NHDF multilayers (Figure 12). During culture, the HUVECs formed tubular structures in the tissues, and highly dense and homogeneous networks were observed upon CLSM examination. Detailed observations indicated that tip and stalk cell-like structures were formed and appeared to be analogous to blood capillaries in vivo. Furthermore, these blood capillaries appeared to have clear lumenal structures in many regions. We observed that both the expression of angiogenic factors from surrounding NHDFs and effect of 3D microenvironments affected 

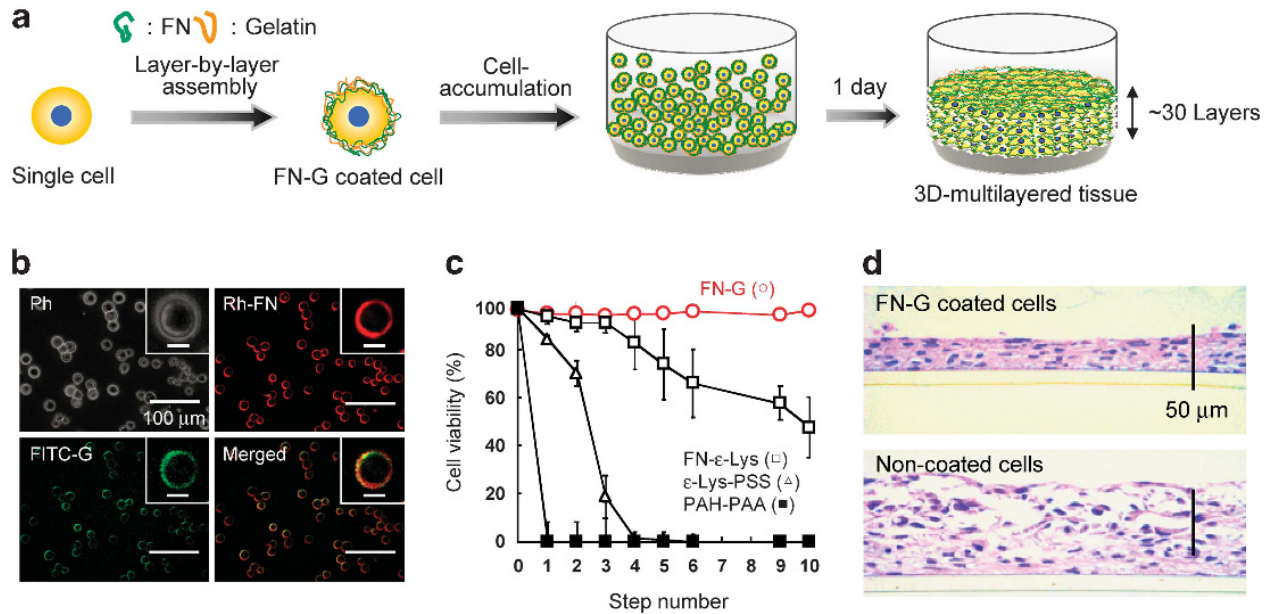

d

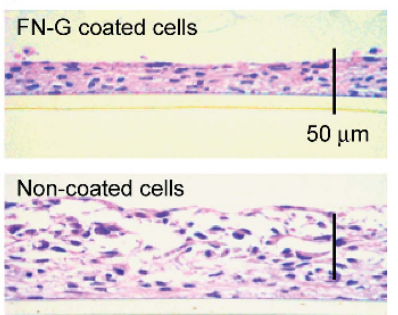

Figure 11 (a) Schematic illustration of the rapid construction of three-dimensional (3D)-multilayered tissues using the cell-accumulation technique using fibronectin (FN)-gelatin (G) nanofilms on a single-cell surface. (b) Phase and fluorescent microscopic images of L929 mouse fibroblast cells coated with a nine-step assembly of rhodamine (Rh)-FN and fluorescein isothiocyanate (FITC)-G. The scale bars in the insets are $10 \mu \mathrm{m}$. (c) Cell viability of L929

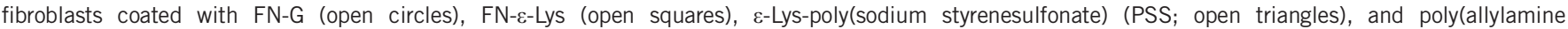
hydrochloride) (PAH)-poly(acrylic acid) (PAA; closed squares) films at each step of the layer-by-layer (LbL) assembly ( $n=3$ ). (d) Hematoxylin and eosin (HE)staining images of the obtained layered human normal dermal fibroblast (NHDF) constructs with or without the nine-step assembled FN-G nanofilm. Reproduced with permission. ${ }^{81}$

a

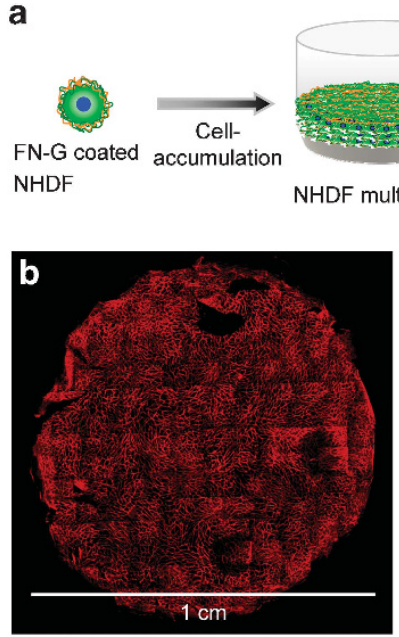

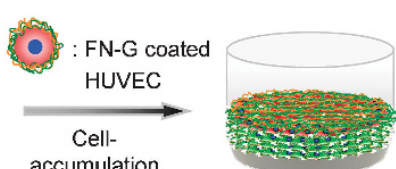
accumulation

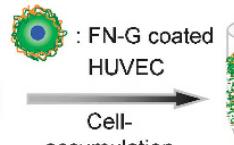

accumulation

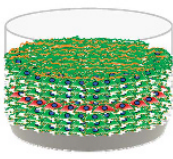

Sandwich culture

HUVEC layer on multilayers
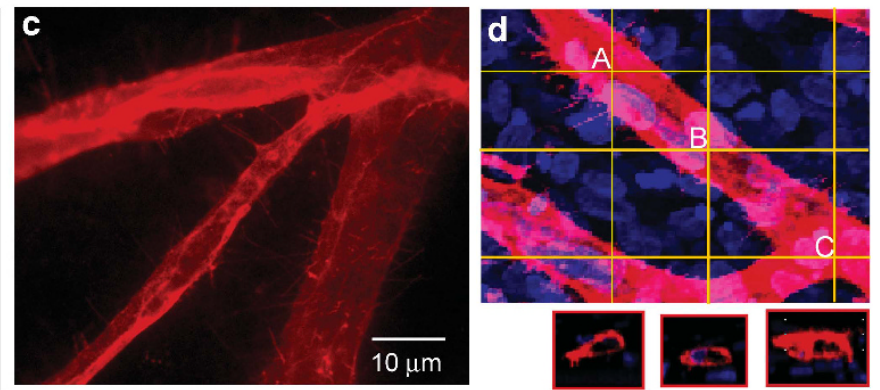

Figure 12 (a) Schematic illustration of a sandwich culture of human umbilical vein endothelial cells (HUVECs) between four-layered (4L) human normal dermal fibroblast (NHDF) tissues. (b) Reconstructed fluorescent image of three-dimensional (3D) tissues with widespread and dense endothelial tube networks. The HUVECs were immunostained with an anti-CD31 antibody (red). This fluorescent image was combined with 150 images at $\times 100$ magnification. (c) Magnified images of the endothelial tubes. (d) CLSM cross-sectional images of the lumenal structures of the endothelial tubes constructed by a sandwich culture of HUVECs between 4 L NHDF layers. The images were acquired from the $x-z$ planes at the A-C positions. Reproduced with permission. ${ }^{81}$

the vascularization by sandwich cultures. ${ }^{83}$ Therefore, such blood capillaries with a lumen have enormous potential for drug permeability testing or tumor angiogenesis and metastasis assays.

\section{SUMMARY}

In this review, the control of extracellular microenvironments by LbL polymer or protein multilayers for tissue engineering application, especially the development of 3D tissue constructs, was described. The FN-based nano-ECM films constructed through biological recognition, which is novel driving force for LbL assembly, allowed us to coat cell surfaces without any damage for the first time. As the nano-ECM exhibited fiber formation on the cell membrane similar to the natural ECM in the body, ${ }^{76}$ the coated cells exhibited high functions, less inflammation and high stability against physical stresses, most likely similar to the real ECM. We discovered the nano-ECM LbL films acted as glue between the cell surfaces because of the biological interaction between the integrin molecules and FN, in the fabrication of 3D cell multilayers. The constructed 3D multicellular architectures exhibited high biological properties and acted as 'human tissue models' for drug responses. Moreover, the sandwich culture of HUVEC between 4L NHDF provided blood capillary formation in the $3 \mathrm{D}$ tissue constructs, and we found that the capillary networks contributed to higher cell viability than that of 3D tissues without any capillary networks (unpublished data). We also reported the rapid and automatic fabrication of 'a human tissue chip' that integrated $>400-\mu \mathrm{m}$-sized 3D tissue constructs for high-throughput drug 
screening assay. ${ }^{84}$ The simple coating techniques reported here have opened a new path as a key technique for control of the extracellular microenvironments in tissue engineering, pharmaceutical and pathophysiological fields.

\section{ACKNOWLEDGEMENTS}

We thank all our colleagues and collaborators on this research project. This work was supported mainly by PRESTO-JST and partly by an Industrial Technology Research Grant Program in 2006 (06B44017a) from NEDO of Japan, a Grant-in-Aid for Scientific Research on Innovative Areas (21106514) from MEXT of Japan, the Noguchi Institute Fund, the NEXT Program from JSPS (LR026) and the SENTAN-JST program (13A1204).

1 Kleinman, H. K., Philp, D. \& Hoffman, M. P. Role of the extracellular matrix in morphogenesis. Curr. Opin. Biotechnol. 14, 526-532 (2003).

2 Lutolf, M. P. \& Hubbell, J. A. Synthetic biomaterials as instructive extracellular microenvironments for morphogenesis in tissue engineering. Nat. Biotech 23, 47-55 (2005).

3 Hynes, R. O. Fibronectins (Springer-Verlag Inc., New York, 1990).

4 Raines, E. W. The extracellular matrix can regulate vascular cell migration, proliferation, and survival: relationships to vascular disease. Int. J. Exp. Pathol. 81, 173-182 (2000).

5 Chen, C. S., Mrksich, M., Huang, S., Whitesides, G. M. \& Ingber, D. E. Geometric control of cell life and death. Science 276, 1425-1428 (1997).

6 Chandra, R. A., Douglas, E. S., Mathies, R. A., Bertozzi, C. R. \& Francis, M. B. Programmable cell adhesion encoded by DNA hybridization. Angew. Chem. Int. Ed. 45, 896-901 (2006).

7 Gong, P., Zheng, W., Huang, Z., Zhang, W., Xiao, D. \& Jiang, X. A strategy for the construction of controlled, three-dimensional, multilayered, tissue-like structures. Adv. Funct. Mater. 23, 42-46 (2013).

8 Teramura, Y. \& Iwata, H. Cell surface modification with polymers for biomedical studies. Soft Mater. 6, 1081-1091 (2010).

9 Decher, G. \& Hong, J. D. Buildup of ultrathin multilayer films by a self-assembly process, 1 consecutive adsorption of anionic and cationic bipolar amphiphiles on charged surfaces. Makromol. Chem. Macromol. Symp. 46, 321-327 (1991).

10 Decher, G. Fuzzy nanoassemblies: toward layered polymeric multicomposites. Science 277, 1232-1237 (1997)

11 Decher, G. \& Schlenoff, J. B. (eds) Multilayer Thin Films (Wiley-VCH, Weinheim, 2003).

12 Lvov, Y., Haas, H., Decher, G., Möhwald, H., Mikhailov, A., Mtchedlishvily, B., Morgunova, E. \& Vainshtein, B. Successive deposition of alternate layers of polyelectrolytes and a charged virus. Langmuir 10, 4232-4236 (1994).

13 Lvov, Y., Ariga, K. \& Kunitake, T. Layer-by-layer assembly of alternate protein/polyion ultrathin films. Chem. Lett. 23, 2323-2326 (1994).

14 Lvov, Y., Ichinose, I., Ariga, K. \& Kunitake, T. Assembly of multicomponent protein films using electrostatic layer-by-layer adsorption. J. Am. Chem. Soc. 117, 61176123 (1995).

15 Yang, H. C., Aoki, K., Hong, H.-G., Sackett, D. D., Arendt, M. F., Yau, S. L., Bell, C. M. \& Mallouk, T. E. Growth and characterization of metal(II) alkanebisphosphonate multilayer thin films on gold surfaces. J. Am. Chem. Soc. 115, 11855-11862 (1993).

16 Yonezawa, T., Onoue, S. \& Kunitake, T. Growth of closely packed layers of gold nanoparticles on an aligned ammonium surface. Adv. Mater. 10, 414-416 (1998).

17 Cheung, J. H., Stockton, W. B. \& Rubner, M. F. Molecular-level processing of conjugated polymers. 3. Layer-by-layer manipulation of polyaniline via electrostatic interactions. Macromolecules 30, 2717-2716 (1997).

18 Wang, L., Wang, Z., Zhang, X., Shen, J., Chi, L. \& Fuchs, H. A new approach for the fabrication of an alternating multilayer film of poly(4-vinylpyridine) and poly(acrylic acid) based on hydrogen bonding. Macromol. Rapid Commun. 18, 509-514 (1997).

19 Shimazaki, Y., Mitsuishi, M., Ito, S. \& Yamamoto, M. Preparation of the layer-by-layer deposited ultrathin film based on the charge-transfer interaction. Langmuir 13, 1385-1387 (1997).

20 Wang, F., Ma, N., Chen, Q., Wang, W. \& Wang, L. Halogen bonding as a new driving force for layer-by-layer assembly. Langmuir 23, 9540-9542 (2007).

21 Feng, Z., Wang, Z., Gao, C. \& Shen, J. Direct covalent assembly to fabricate microcapsules with ultrathin walls and high mechanical strength. Adv. Mater. 19, 3687-3691 (2007).

22 Ochs, C. J., Such, G. K., Yan, Y., Koeverden, M. P. \& van Caruso, F. Biodegradable click capsules with engineered drug-loaded multilayers. ACS Nano 4, 1653-1663 (2010).

23 Serizawa, T., Hamada, K.-i., Kitayama, T., Fujimoto, N., Hatada, K. \& Akashi, M. Stepwise stereocomplex assembly of stereoregular poly(methyl methacrylate)s on a substrate. J. Am. Chem. Soc. 122, 1891-1899 (2000).

24 Serizawa, T., Hamada, K.-i., Kitayama, T. \& Akashi, M. Recognition of stereoregular polymers by using structurally regulated ultrathin polymer films. Angew. Chem. Int. Ed. 42, 1118-1121 (2003).
25 Serizawa, T., Hamada, K.-i. \& Akashi, M. Polymerization within a molecularscale stereoregular template. Nature 429, 52-55 (2004).

26 Serizawa, T., Yamashita, H., Fujiwara, T., Kimura, Y. \& Akashi, M. Stepwise assembly of enantiomeric poly(lactide)s on surfaces. Macromolecules 34, 1996-2001 (2001).

27 Neu, B., Voigt, A., Mitröhner, R., Leporatti, S., Gao, C. Y., Donath, E., Kiesewetter, H., Möhwald, H., Meiselman, H. J. \& Bäumler, H. Biological cells as templaes for hollow microcapsules. J. Microencapsulation 18, 385-395 (2001).

28 Diaspro, A., Silvano, D., Krol, S., Cavalleri, O. \& Gliozzi, A. Single living cell encapsulation in nano-organized polyelectrolyte shells. Langmuir 18, 5047-5050 (2002).

29 Chanana, M., Gliozzi, A., Diaspro, A., Chodnevskaja, I., Huewel, S., Moskalenko, V., Ulrichs, K., Galla, H.-J. \& Krol, S. Interaction of polyelectrolytes and their composites with living cells. Nano Lett. 5, 2605-2612 (2005).

30 Veerabadran, N. G., Goli, P. L., Stewart-Clark, S. S., Lvov, Y. M. \& Mills, D. K. Nanoencapsulation of stem cells within polyelectrolyte multilayer shells. Macromol. Biosci. 7, 877-882 (2007)

31 Decher, G., Lehr, B., Lowack, K., Lvov, Y. \& Schmitt, J. Biosens. Bioelectron. 9, 677-684 (1994).

32 He, P.-G., Takahashi, T., Hoshi, T., Anzai, J., Suzuki, Y. \& Osa, T. Preparation of enzyme multilayers on electrode surface by use of avidin and biotin-labeled enzyme for biosensor applications. Mater. Sci. Eng C2, 103-106 (1994).

33 Ebato, H., Herron, J. N., Muller, W., Okahata, Y., Ringsdorf, H. \& Suci, P. Docking of a second functional protein layer to a streptavidin matrix on a solid support: studies with a quartz crystal microbalance. Angew. Chem. Int. Ed. 31, 1087-1090 (1992).

34 Anzai, J., Kobayashi, Y., Nakamura, N., Nishimura, M. \& Hoshi, T. Layer-by-layer construction of multilayer thinfilms composed of avidin and biotin-labeled poly(amine)s. Langmuir 15, 221-226 (1999).

35 Bourdillon, C., Demaille, C., Miroux, J. \& Savéant, J. M. Step-by-step immunological construction of a fully active multilayer enzyme electrode. J. Am. Chem. Soc. 116, 10328-10329 (1994).

36 Bourdillon, C., Demaille, C., Moiroux, J. \& Saveant, J.-M. Catalysis and mass transport in spatially ordered enzyme assemblies on electrodes. J. Am. Chem. Soc. 117, 11499-11506 (1995).

37 Anzai, J., Kobayashi, Y. \& Nakamura, N. Alternate deposition of concanavalin A and mannose-labeled enzymes on a solid surface to prepare catalytically active enzyme thin films. J. Chem. Soc., Perkin Trans 2, 461-462 (1998).

38 Zhu, Y., Tong, W. \& Gao, C. Molecular-engineered polymeric microcapsules assembled from concanavalin $A$ and glycogen with specific responses to carbohydrates. Soft Mater. 7, 5805-5815 (2011).

39 Mhanna, R. F., Vörös, J. \& Zenobi-Wong, M. Layer-by-layer films made from extracellular matrix macromolecules on silicone substrates. Biomacromolecules 12 , 609-616 (2011).

40 Ruoslahti, E. \& Pierschbacher, M. D. New perspectives in cell adhesion: RGD and integrins. Science 238, 491-497 (1987).

41 Nakahara, Y., Matsusaki, M. \& Akashi, M. Fabrication and enzymatic degradation of fibronectin-based ultrathin films. J. Biomater. Sci. Polymer Edn 18, 1565-1573 (2007).

42 Matsusaki, M., Ajiro, H., Kida, T., Serizawa, T. \& Akashi, M. Layer-by-layer assembly through weak interactions and their biomedical applications. Adv. Mater. 24, 454-474 (2012).

43 Natali, P. G., Galloway, D., Nicotra, M. R. \& Martino, C. Topographic association of fibronectin wit elastic fibers in the arterial wall. An immunohistochemical study. Connect. Tissue Res. 8, 199-204 (1981).

44 Bonnefoy, A. \& Legrand, C. Proteolysis of subendothelial adhesive glycoproteins (fibronectin, thrombospondin, and von Willebrand factor) by plasmin, leukocyte, cathepsion G, and elastase. Thrombosis Res. 98, 323-332 (2000).

45 Ngankam, A. P., Mao, G. \& van Tassel, P. R. Fibronectin adsorption onto polyelectrolyte multilayer films. Langmuir 20, 3362-3370 (2002).

46 Rajagopalan, P., Shen, C. J., Berthiaume, F., Tilles, A. W., Toner, M. \& Yarmush, M. L. Polyelectrolyte nano-scaffolds for the design of layered cellular architectures. Tissue Eng. 12, 1553-1563 (2006).

47 Fischer, D., Li, Y., Ahlemeyer, B., Krieglstein, J. \& Kissel, T. In vitro cytotoxicity testing of polycations: influence of polymer structure on cell viability and hemolysis. Biomaterials 24, 1121-1131 (2003).

48 Kadowaki, K., Matsusaki, M. \& Akashi, M. Control of cell surface and functions by layer-by-layer nanofilms. Langmuir 26, 5670-5678 (2010).

49 Matsusaki, M. Development of three-dimensional tissue models based on hierarchical cell manipulation using nanofilms. Bull. Chem. Soc. Jpn 85, 401-414 (2012)

50 Kadowaki, K., Matsusaki, M. \& Akashi, M. Control of cellular inflammation by layer-bylayer nanofilms through different driving forces. Chem. Lett. 41, 523-524 (2012).

51 Cui, X., Dean, D., Ruggeri, Z. M. \& Boland, T. Cell damage evaluation of thermal inkjet printed Chinese hamster ovary cells. Biotechnol. Bioeng. 106, 963-969 (2010).

52 Matsuzawa, A., Matsusaki, M. \& Akashi, M. Effectiveness of nanometer-sized extracellular matrix layer-by-layer assembled films for a cell membrane coating protecting cells from physical stress. Langmuir 29, 7362-7368 (2013).

53 Drewe, J. \& Cai, X. Cell-based apoptosis assays in oncology drug discovery. Expert. Opin. Drug Discov. 5, 583-596 (2010).

54 Michelini, E., Cevenini, L., Mezzanotte, L., Coppa, A. \& Roda, A. Cell-based assays: fuelling drug discovery. Anal. Bioanal. Chem. 398, 227-238 (2010).

55 Commission staff working documents, Time tables for the phasing-out of animal testing in the framework of the 7th amendment to the cosmetics directive (council directive 76/768/EEC; EN, SEC82004) 2004, 1210. http://ec.europa.eu/consumers/sectors/ cosmetics/documents/directive/index en.htm.

56 Debnath, J. \& Brugge, J. S. Modelling glandular epithelial cancers in three-dimensional culture. Nat. Rev. Cancer 5, 675-688 (2005). 
57 Lee, G. Y., Kenny, P. A., Lee, E. H. \& Bissell, M. J. Three-dimensional culture models of normal and malignant breast epithelial cells. Nat. Methods 4, 359-365 (2007).

58 Dolznig, H., Walzl, A., Kramer, N., Rosner, M., Garin-Chesa, P. \& Hengstschläger, M. Organotypic spheroid cultures to study tumor-stroma interaction during cancer development. Drug Discov. Today Dise. Mod. 8, 113-119 (2011).

59 Koide, N., Shinji, T., Tanabe, T., Asano, K., Kawaguchi, M., Sakaguchi, K., Koide, Y., Mori, M. \& Tsuji, T. Continued high albumin production by multicellular spheroids of adult rat hepatocytes formed in the presence of liver-derived proteoglycans. Biochem. Biophys. Res. Commun. 161, 385 (1989).

60 Otsuka, H., Hirano, A., Nagasaki, Y., Okano, T., Horiike, Y. \& Kataoka, K. Twodimensional multiarray formation of hepatocyte spheroids on a microfabricated PEGbrush surface. Chem. Bio. Chem. 5, 850-855 (2004).

61 de Ridder, L., Cornelissen, M. \& de Ridder, D. Autologous spheroid culture: a screening tool for human brain tumor invation. Crit. Rev. Oncol. Hematol. 36, 107-122 (2000).

62 Brabletz, T., Jung, A., Reu, S., Porzner, M., Hlubek, F., K.-Schughart, L. A., Knuechel, R. \& Kirchner, T. Variable $\beta$-catenin expression in colorectal cancers indicates tumor progression driven by the tumor environment. Proc. Natl Acad. Sci. USA 98, 10356-10361 (2001).

63 Lu, H. F., Chua, K. N., Zhang, P. C., Lim, W. S., Ramakrishna, S., Leong, K. W. \& Mao, H. O. Three-dimensional co-culture of rat hepatocyte spheroids and NIH/3T3 fibroblasts enhances hepatocyte functional maintenance. Acta Biomater. 1, 399-410 (2005).

64 Goodman, T. T., Ng, C. P. \& Pun, S. H. 3-D tissue culture systems for the evaluation and optimization of nanoparticle-based drug carriers. Bioconjugate Chem. 19, 19511959 (2008)

65 Matsusaki, M., Kadowaki, K., Nakahara, Y. \& Akashi, M. Fabrication of cellular multilayers with nanometer-sized extracellular matrix films. Angew. Chem. Int. Ed. 46, 4689-4692 (2007)

66 Ito, A., Jitsunobu, H., Kawabe, Y. \& Kamihira, M. Construction of heterotypic cell sheets by magnetic force-based 3-D coculture of HepG2 and NIH3T3 cells. J. Biosci. Bioeng. 104, 371-378 (2007).

67 Harimoto, M., Yamato, M., Hirose, M., Takahashi, C., Isoi, Y., Kikuchi, A. \& Okano, T. Novel approach for achieving double-layered cell sheets co-culture: overlaying endothelial cell sheets onto monolayer hepatocytes utilizing temperature-responsive culture dishes. J. Biomed. Mater. Res. 62, 464-470 (2002).

68 L'Heureux, N., Stoclet, J. C., Auger, F. A., Lagaud, G. J., Gemain, L. \& Andriantsitohaina, R. A human tissue-engineered vascular media: a new model for pharmacological studies of contractile responses. FASEB J 15, 515-524 (2001).

69 Kadowaki, K., Matsusaki, M. \& Akashi, M. Three-dimensional constructs induce high cellular activity: structural stability and the specific production of proteins and cytokines. Biochem. Biophys. Res. Commun. 402, 153-157 (2010).

70 Alderton, W. K., Cooper, C. E. \& Knowles, R. G. Nitric oxide synthases: structure, function and inhibition. Biochem. J. 357, 593-615 (2001).
71 Zhao, G., Zhang, X., Smith, C. J., Xu, X., Ochoa, M., Greenhouse, D., Vogel, T., Curran, C. \& Hintze, T. H. Reduced coronary NO production in conscious dogs after the development of alloxan-induced diabetes. Am. J. Physiol. 277, H268-H278 (1999).

72 Kurioka, S., Koshimura, K., Murakami, Y., Nishiki, M. \& Kato, Y. Reverse correlation between urine nitric oxide metabolites and insulin resistance in patients with type 2 diabetes mellitus. Endocr. J. 47, 77-81 (2000).

73 Nakaya, Y., Minami, A., Harada, N., Sakamoto, S., Niwa, Y. \& Ohnaka, M. Taurine improves insulin sensitivity in the Otsuka Long-Evans Tokushima Fatty rat, a model of spontaneous type 2 diabetes. Am. J. Clin. Nutr. 71, 54-58 (2000).

74 Nakatsubo, N., Kojima, H., Kikuchi, K., Nagoshi, H., Hirata, Y., Maeda, D., Imai, Y., Irimura, T. \& Nagano, T. Direct evidence of nitric oxide production from bovine aortic endothlial cells using new fluorescence indicators: diaminofluoresceins. FEBS Lett. 427, 263-266 (1998).

75 Amemori, S., Matsusaki, M. \& Akashi, M. Biocompatible and highly sensitive nitric oxide sensor particles prepared by layer-by-layer assembly. Chem. Lett. 39, 42-43 (2010).

76 Matsusaki, M., Kadowaki, K., Adachi, E., Sakura, T., Yokoyama, U., Ishikawa, Y. \& Akashi, M. Morphological and histological evaluations of 3D-layered blood vessel constructs prepared by hierarchical cell manipulation. J. Biomater. Sci. Polymer Edn 23, 63-79 (2012).

77 Matsusaki, M., Amemori, S., Kadowaki, K. \& Akashi, M. Quantitative 3D analysis of nitric oxide diffusion in a 3D artery model using sensor particles. Angew. Chem. Int Ed. 50, 7557-7561 (2011).

78 Kikuchi, K., Nagano, T. \& Hirobe, M. Novel detection method of nitric oxide using horseradish peroxidase. Biol. Pharm. Bull. 19, 649-651 (1996).

79 Malinski, T. \& Taha, Z. Nitric oxide release from a single cell measured in situ by a porphyrinic-based microsensor. Nature 358, 676-678 (1992).

80 Ortiz, P. A., Hong, N. J. \& Garvin, J. L. Luminal flow induce eNOS activation and traslocation in the rat thick ascending limb. II. Role of PI3-kinase and Hsp90. Am. J. Physiol. Renal. Physiol. 287, F274-F280 (2004).

81 Malinsk, T., Taha, Z. \& Grunfeld, S. Diffusion of nitric oxide in the aorta wall monitored in situ by porphyrinic microsensors. Biochem. Biophys. Res. Commun. 193, 1076-1082 (1993).

82 Nishiguchi, A., Yoshida, H., Matsusaki, M. \& Akashi, M. Rapid construction of threedimensional multilayered tissues with endothelial tube networks by the cell-accumulation technique. Adv. Mater. 23, 3506-3510 (2011).

83 Nishiguchi, A., Matsusaki, M., Asano, Y., Shimoda, H. \& Akashi, M. Effects of angiogenic factors and 3D-microenvironments on vascularization within sandwich cultures. Biomaterials 35, 4739-4748 (2014).

84 Matsusaki, M., Sakaue, S., Kadowaki, K. \& Akashi, M. Three-dimensional human tissue chips fabricated by rapid and automatic inkjet cell printing. Adv. Healthcare Mater. 2, 534-539 (2013).

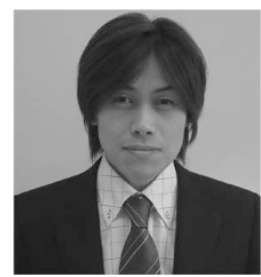

Michiya Matsusaki received his PhD degree in 2003 under the direction of Prof Mitsuru Akashi from Kagoshima University, Japan. He started his academic carrier as a Japan Society for the Promotion of Science postdoctoral fellow at Osaka University from 2003 to 2005 During this period, he was a visiting scientist of Prof Carl A. K. Borrebaeck laboratory in 2004 in Lund University, Sweden. In 2005, he joined the Department of Applied Chemistry in the Graduate School of Engineering at Osaka University as a designated assistant professor. Since 2006, he has been an assistant professor of the department. He was a PRESTO researcher of JST as a concurrent position from 2008 to 2010. His research interests functional polymers and biomaterials for biomedical and tissue engineering applications. He has received Young Scientist Lecture Award in The 52nd Polymer Research Symposium (Kobe) (2006), The Chemical Society of Japan Award for Young Chemists (2010), Osaka University Achievement Award in Research (2011) and Osaka University Presidential Awards for Encouragement (2013).

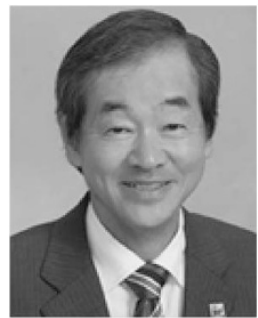

Mitsuru Akashi received his PhD degree in 1978 in Engineering from Osaka University, Japan. He was a post-doc at NIH, Gerontology Research Center (USA) and the University of Waterloo (Canada) in 1978-1980. He joined the Department of Applied Chemistry and Chemical Engineering, Faculty of Engineering, Kagoshima University, as an assistant Professor in 1981. He was promoted to associate Professor in 1984 and a full professor in 1989. From 2003, he is a full Professor for the Department of Applied Chemistry, Graduate School of Engineering, Osaka University. His research interests cover the design and synthesis of functional polymers and preparation of novel biomaterials, including synthesis of nanoparticles, gels and so on. He has received The Award of the Society of Polymer Science, Japan (1999) and The Award of the Japanese Society for Biomaterials (2004). He is the 31st Presidency of the Society of Polymer Science, Japan. 